\title{
Enhanced Photocatalytic Performance in Chromium(Vl) Reduction and Dye Degradation using Sn304/SnS2 Nanocomposite and Mechanism Insight
}

\section{Gandharve Kumar}

Indian Institute of Technology Roorkee

Rajkumar Dutta ( $\nabla$ r.dutta@cy.iitr.ac.in )

Indian Institute of Technology Roorkee https://orcid.org/0000-0001-9667-0399

\section{Research Article}

Keywords: Sn304/SnS2 nanocomposite, solar photocatalyst, Z-scheme heterojunction, photocatalytic reduction of $\mathrm{Cr}(\mathrm{VI})$ and photocatalytic degradation of methylene blue, degradation product analysis by UPLC-Q-Tof-MS

Posted Date: December 23rd, 2021

DOI: https://doi.org/10.21203/rs.3.rs-1107930/v1

License: (c) (i) This work is licensed under a Creative Commons Attribution 4.0 International License.

Read Full License 


\section{Enhanced photocatalytic performance in chromium (VI) reduction and dye}

\section{2 degradation using $\mathrm{Sn}_{3} \mathrm{O}_{4} / \mathrm{SnS}_{2}$ nanocomposite and mechanism insight}

3 Gandharve Kumar ${ }^{1}$, Raj Kumar Dutta ${ }^{1,2, *}$

$4 \quad{ }^{1}$ Centre of Nanotechnology, Indian Institute of Technology Roorkee, Roorkee-247667, India

$5 \quad{ }^{2}$ Department of Chemistry, Indian Institute of Technology Roorkee, Roorkee-247667, India

$6 *$ Author for Correspondence: Email: $\underline{\text { r.dutta@cy.iitr.ac.in (R.K. Dutta) }}$

\section{Abstract}

8 Detection of residual organic and inorganic species in water bodies including drinking water 9 has led to developing strategies for their removal. Here we report a very efficient method of photoreduction of $\mathrm{Cr}(\mathrm{VI})$ and photodegradation of methylene blue dye in aqueous medium using Z-scheme heterojunction based $\mathrm{Sn}_{3} \mathrm{O}_{4} / \mathrm{SnS}_{2}$ solar photocatalyst. The photocatalyst is synthesized by hydrothermal route and it is thoroughly characterized in terms of its structural, compositional, morphological and optical properties. About $100 \%$ of $\mathrm{Cr}$ (VI) reduction in 60 min and $99.6 \%$ of methylene blue degradation in $90 \mathrm{~min}$ is achieve under sunlight exposure at a photocatalytic rate of $0.066 \mathrm{~min}^{-1}$ and $0.043 \mathrm{~min}^{-1}$, respectively. The total organic carbon estimation of the post-degradation reaction medium corresponded to $85.1 \%$ (MB) mineralization. The photocatalytic degradation is attributed to in-situ generation of reactive oxygen species (ROS) e.g., superoxide radicals, hydroxide radicals, and the role of ROS towards reduction and degradation of $\mathrm{Cr}(\mathrm{VI})$ and $\mathrm{MB}$ respectively, is confirmed from ROS scavenging studies. The dye degradation mechanism has been discussed by analyzing the degradation products via UPLC-Q-Tof-MS. The photocatalytic degradation of methylene blue by $\mathrm{Sn}_{3} \mathrm{O}_{4} / \mathrm{SnS}_{2}$ nanocomposites is significantly enhanced as compared to $\mathrm{SnS}_{2}$ photocatalyst, attributed to Z-scheme heterojunction and the charge carrier mobility. 
$\mathrm{Sn}_{3} \mathrm{O}_{4} / \mathrm{SnS}_{2}$ nanocomposite, solar photocatalyst; $\mathrm{Z}$-scheme heterojunction; photocatalytic reduction of $\mathrm{Cr}(\mathrm{VI})$ and photocatalytic degradation of methylene blue; degradation product analysis by UPLC-Q-Tof-MS.

Introduction

Water bodies contaminated with inorganic and organic species has a cascading impact on ecosystem and also a major cause of human health hazard (Barrera-Díaz et al. 2012; Coetzee et al. 2020; Tumolo et al. 2020). Among these, $\mathrm{Cr}$ (VI) and organic dyes in industrial as well as municipal wastewater are some of the most common constitutents owing to their wide range of usages. For example, Cr (VI) compounds are used in electroplating, leather tanning, metal finishing, textile production, and dyeing (He et al. 2020; Karimi-Maleh et al. 2021). Consequently, large volumes of aqueous chromium wastes are generated and discharged into the environment without pretreatment (Owlad et al. 2009). Chromium compounds mostly exist in two standard oxidation states, i.e., $\mathrm{Cr}$ (III) and $\mathrm{Cr}$ (VI). Out of which, $\mathrm{Cr}$ (VI) is water soluble and it is highly toxic owing to its carcinogenic nature (Sedman et al. 2006; Narayani and Shetty 2013). On the other hand, Cr (III) is less toxic and can readily be precipitated out of a solution as $\mathrm{Cr}(\mathrm{OH})$ (Mertz 1993). Similarly, organic dyes are widely used in textile industries for the colouring of fabrics such silk, cotton and wool etc (Khatri et al. 2015). These dyes are generally stable, highly water soluble, non-biodegradable and carcinogenic in nature, and hence they are hazardous to human and aquatic species (Gusain et al. 2019; Yaseen and Scholz 2019). This demands scientific attention for developing efficient technologies for removal or elimination of $\mathrm{Cr}$ (VI) and organic dyes from wastewater. The conventional remediation processes such coagulation, adsorption, membrane separation and precipitation are insufficient for complete removal of the 
hexavalent chromium and organic dyes from water and wastewater (Hafiane et al. 2000; Katheresan et al. 2018). The efficiency of biodegradation of $\mathrm{Cr}$ (VI) and organic dyes is low. In view of this, advanced oxidation process (AOP) is considered to be more efficient, particularly for treating organic pollutants as it tends to mineralize the pollutants (Bethi et al. 2016). However, AOP is associated to higher operational cost and due to generation of secondary wastes. Alternately, heterogeneous semiconductor-based photocatalysis have gained major attention from the researchers for the treatment of polluted wastewater as it also has the capacity to mineralize the organic constituents (Saadati et al. 2016; Calvete et al. 2019; Di et al. 2019; Wei et al. 2020). Here light of energy greater than the band gap of the photocatalyst is needed for generating electrons and holes which are retained in thermodynamically favorable band edges, i.e., conduction band of one semiconductor materials and valence band of the other semiconducting material (Zhang et al. 2020; Wang et al. 2021). The charge carriers can diffuse to the outer surface of the photocatalyst to interact with $\mathrm{H}_{2} \mathrm{O}$ and molecular oxygen at the outer surface of the photocatalyst to produce highly reactive oxygen speicies (ROS). This ROS in turn can cleave the bonds of the pollutants (e.g., dye molecules) and eventually mineralize. The major hurdles this system is associated with favourable recombination of charge carriers, loss of charge carriers due to their trapping in defect sites, poor redox property owing to band energy mismatch for ROS generation (Das and Dutta 2015; Sharma and Dutta 2018; Wang et al. 2020). In addition, most photocatalytic degradation studies are based on UV light exposure, which is a major limitation from solar harvesting technology point of view as only $6 \%$ of the sunlight constitutes UV range (Mukherjee et al. 2021). Considering all the above conditions, it may be put forward that Ztype heterojunction based photocatalyst is favourable for enhancing photocatalytic performance as demonstrated in literature (Qiang et al. 2021). The main advantage with these Z-type heterojunction is attributed to efficient inhibition of charge carrier recombination and 
also decrease the defect state density (Lin et al. 2021). It is mostly found that the photocatalysts with Z-type heterojunction are made of oxides like (Li et al. 2016; Huang et al. 2019; Zhao et al. 2019; Xu et al. 2020). Contrastingly, studies based on Z-type photocatalyst made of oxides-sulphide mixed systems are much less (Di et al. 2019). One of the main concern here is the stability of the sulphide component. Considering these conditions, we present here a novel Z-type heterojunction photocatalyst comprising a low band gap $\mathrm{SnS}_{2}$ as a base material in combination with $\mathrm{Sn}_{3} \mathrm{O}_{4}$ which is a large band gap materials. The photocatalyst, represented as $\mathrm{Sn}_{3} \mathrm{O}_{4} / \mathrm{SnS}_{2}$ nanocomposites, has been thoroughly characterized and was studied sunlight mediated photoreduction of hexavalent chromium $\mathrm{Cr}$ (VI) and photocatalytic degradation of organic dye in aqueous medium. Hexavalent Chromium Cr (VI) and methylene blue has been chosen as a model pollutants, as it has been detected in ecosystem comprising river water, ground water, sediments and soils, and in drinking water (Fick et al. 2009; Sharma and Bhattacharya 2017; Singh et al. 2019; Khan et al. 2020). The detailed methodology for synthesis, characterization and photocatalytic degradation kinetics by $\mathrm{Sn}_{3} \mathrm{O}_{4} / \mathrm{SnS}_{2}$ nanocomposites has been discussed. The mechanism of photocatalytic degradation of methylene blue has been discussed in the light of in-situ generated reactive oxygen species (ROS) and identification of degradation products by UPLC-Q-Tof-MS technique.

\section{Experimental section}

\section{Chemicals}

Stannous chloride dihydrate (98\%),stannous chloride pentahydrate (98\%),thioacetamide, sodium hydroxide, trisodium citrate, diphenylcarbazide, chloroform, tert-butanol, ammonium oxalate, potassium dichromate, and ethanol (99\%) were procured from HiMedia Pvt. Ltd., India. All precursors used in this study were of analytical grade and 
were used without further purification. Analytical grade deionized water (Millipore) was used throughout the study.

\section{Synthesis $\mathrm{Sn}_{3} \mathrm{O}_{4} / \mathrm{SnS}_{2} \mathrm{NCs}$}

It is a two-step process, where $\mathrm{Sn}_{3} \mathrm{O}_{4}$ nanoflakes were first prepared via hydrothermal route. In a typical process, $4 \mathrm{mmol}$ of Stannous chloride dihydrate was dissolved in $12.5 \mathrm{~mL}$ deionized water than $12.5 \mathrm{mmol}$ tri-sodium citrate dihydrate was added and stirred until a transparent solution was obtained, then $0.1 \mathrm{~g}$ of sodium hydroxide dissolved in $12.5 \mathrm{~mL}$ D.I water, was added to the above solution dropwise and stir for $1 \mathrm{~h}$ and finally transfer the solution into a $50 \mathrm{~mL}$ Teflon jar and heated at $180{ }^{\circ} \mathrm{C}$ for $12 \mathrm{~h}$ in a microprocessor-based temperature-controlled furnace. Finally, the autoclave was cooled to room temperature. The resulting solution of $\mathrm{Sn}_{3} \mathrm{O}_{4}$ was then precipitated with ethanol and recovered by centrifuging at 15,000 rpm for $5 \mathrm{~min}$. The batch of $\mathrm{Sn}_{3} \mathrm{O}_{4}$ was washed several times with ethanol and then dried overnight in oven at $40^{\circ} \mathrm{C}$.

Next $5.0 \mathrm{mmol} \mathrm{SnCl}_{4} .5 \mathrm{H}_{2} \mathrm{O}$ was dissolved in $40 \mathrm{~mL}$ deionized water than $12.5 \mathrm{mmol}$ of Thioacetamide was added and stir until a homogenous solution was formed. After that, a definite wt. $\%$ of $\mathrm{Sn}_{3} \mathrm{O}_{4}$ (i.e., 5 wt. $\%, 7$ wt. $\%$ and 10 wt. $\%$ ) was added to the above solution mixture under constant stirring. The whole mixture was then transferred to an autoclave and heated at $180^{\circ} \mathrm{C}$ for $8 \mathrm{~h}$. The obtained precipitate was washed with deionised water and ethanol by centrifuging at $7000 \mathrm{rpm}$ for $10 \mathrm{~min}$ and the final yellow product was dried at $60^{\circ} \mathrm{C}$ overnight. The nanocomposites will be denoted as $0.05 \mathrm{Sn}_{3} \mathrm{O}_{4} / \mathrm{SnS}_{2}, 0.07 \mathrm{Sn}_{3} \mathrm{O}_{4} / \mathrm{SnS}_{2}$ and $0.10 \mathrm{Sn}_{3} \mathrm{O}_{4} / \mathrm{SnS}_{2}$ according to the wt.\% of precursor $\mathrm{Sn}_{3} \mathrm{O}_{4}$ added. Likewise, control batch of pristine $\mathrm{SnS}_{2}$ was prepared following the same synthetic protocol without the addition of $\mathrm{Sn}_{3} \mathrm{O}_{4}$ nanoparticles. 


\section{Characterization's techniques}

The as-synthesized batches of $\mathrm{Sn}_{3} \mathrm{O}_{4} / \mathrm{SnS}_{2}$ NCs with different $\mathrm{Sn}_{3} \mathrm{O}_{4}$ weight ratios, together with those of $\mathrm{SnS}_{2}$ nanoparticles, $\mathrm{Sn}_{3} \mathrm{O}_{4}$ nanoparticles are characterized by powder X-ray Diffraction, X-ray photoelectron spectroscopy, field emission scanning electron microscopy, high resolution transmission electron microscopy, Brunauer-Emmett-Teller (BET) specific surface area technique, photoluminescence spectroscopy, electrochemical impedance spectroscopy and by diffused reflectance spectroscopy. The details of these techniques and sample preparation are given as Supporting Information (Section S1).

The degradation intermediates were identified by UPLC (ACQUITY I) coupled to QToF (XeVO G2-XS QToF). Mobile phase A was aqueous formic acid solution $(0.1 \%$, v/v), and mobile phase B was acetonitrile. The gradient solvent was at a flow rate of $0.3 \mathrm{~mL} / \mathrm{min}$. The MS was performed in a positive ion mode using an electrospray ionization (ESI+) source under the following conditions: capillary voltage: $2.0 \mathrm{kV}$; gas $\left(\mathrm{N}_{2}\right)$ flow rate: $50 \mathrm{~L} / \mathrm{h}$; gas temperature: $300{ }^{\circ} \mathrm{C}$; nebulization pressure: 15 psi; scan time: 0.5 second.

\section{Evaluation of Photocatalytic activity}

The photocatalytic activities of the $\mathrm{Sn}_{3} \mathrm{O}_{4} / \mathrm{SnS}_{2} \mathrm{NCs}$ and their respective individual components (e.g., $\mathrm{Sn}_{3} \mathrm{O}_{4} \mathrm{NPs}, \mathrm{SnS}_{2} \mathrm{NPs}$ ) as photocatalysts were evaluated by monitoring the photocatalytic reduction of $\mathrm{Cr}(\mathrm{VI})$ solution $\left(50 \mathrm{mg} \mathrm{L}^{-1}\right)$ under natural sunlight irradiation. In a typical experiment, first, the $\mathrm{pH}$ of the initial $100 \mathrm{~mL} \mathrm{Cr}$ (VI) solution was adjusted to 2.5 by adding $1 \mathrm{M} \mathrm{H}_{2} \mathrm{SO}_{4}$ solution, then $50 \mathrm{mg}$ of respective photocatlyst were dispersed in the batches of $\mathrm{Cr}(\mathrm{VI})$ solution $\left(50 \mathrm{mg} / \mathrm{L}\right.$ based on $\mathrm{Cr}$ in $\mathrm{K}_{2} \mathrm{Cr}_{2} \mathrm{O}_{7}$ solution) taken in $250 \mathrm{~mL}$ beakers. This will be referred to as reaction assembly, which was subjected to slow continuous stirring (less than $100 \mathrm{rpm}$ ) for $60 \mathrm{~min}$ in dark condition to establish adsorptiondesorption equilibrium. After $60 \mathrm{~min}$ the reaction assemblies was kept under natural sunlight 
(photocatalytic experiments were carried out at IIT Roorkee $\left(29^{\circ} 51^{\prime} \mathrm{N} ; 77^{\circ} 53^{\prime} \mathrm{E}\right)$ in the month of April and May 2021. The solar irradiance was assumed to be $221 \mathrm{~W} / \mathrm{m}^{2}$ during the experiment day (Ramachandra et al. 2011). At regular intervals, $1.5 \mathrm{~mL}$ of the suspension was withdrawn from each reaction assembly and centrifuged at $15000 \mathrm{rpm}$ for $2 \mathrm{~min}$ to discard any particles using Beckman Coulter Allegra TM X-22R. The concentration of $\mathrm{Cr}$ (VI) was monitored according to the previously reported method (Zhang et al. 2019). First, $1.0 \mathrm{ml}$ of the sample was mixed with $9 \mathrm{ml}$ of $0.2 \mathrm{M} \mathrm{H}_{2} \mathrm{SO}_{4}$ in a $10.0 \mathrm{ml}$ volumetric flask. Subsequently, $0.2 \mathrm{ml}$ of freshly prepared 1,5-diphenylcarbazide $(250 \mathrm{mg} / 50 \mathrm{~mL})$ solution was added to the above mixture. After shaking up the mixture, the solution was allowed to stand for 10-15 min to ensure full-color development. Subsequently, the solution was measured at $540 \mathrm{~nm}$ by UV-vis spectrophotometer (Shimadzu, UV-2400, Japan). The effect of solution $\mathrm{pH}$ on the photoreduction efficiency of $\mathrm{Cr}(\mathrm{VI})$ was investigated under the same condition. The chromium solution with different $\mathrm{pH}$ was adjusted by $0.2 \mathrm{M} \mathrm{H}_{2} \mathrm{SO}_{4}$ or $\mathrm{NaOH}$.

Organic dye methylene blue (MB) was selected as another target pollutant. The degradation UV-Vis spectrophotometer (UV-1800, Shimadzu, Japan).

The leached concentrations of respective constituents in the photocatalysts, viz. Sn 167 from the batch of $\mathrm{Cr}(\mathrm{VI})$ solution treated with $0.07 \mathrm{Sn}_{3} \mathrm{O}_{4} / \mathrm{SnS}_{2} \mathrm{NCs}$ were determined by ICP-OES. The details of sample preparation are given as supporting information (Section 
$0.07 \mathrm{Sn}_{3} \mathrm{O}_{4} / \mathrm{SnS}_{2} \mathrm{NCs}$ was assessed by monitoring photocatalytic reduction of $\mathrm{Cr}$ (VI) for five successive cycles. At the end of each cycle, the used photocatalyst was recovered, dried, and reused for the next cycle. After completing five cycles of photocatalytic reduction, the stability of the photocatalyst was studied by XRD and FESEM.

\section{Results and Discussion}

The powder X-ray diffraction (XRD) method was used to investigate the crystalline structure and phase composition of the as-synthesized batches of $\mathrm{Sn}_{3} \mathrm{O}_{4}, \mathrm{SnS}_{2}$ and the $\mathrm{Sn}_{3} \mathrm{O}_{4} / \mathrm{SnS}_{2}$ NCs. The characteristic Bragg reflection peaks for pristine $\mathrm{SnS}_{2}$ were detected at $2 \theta=14.8^{\circ}, 28.1^{\circ}, 32.0^{\circ}, 33.5^{\circ}, 46.0^{\circ}, 49.9^{\circ}$ and $52.4^{\circ}$ (Fig. 1$)$, which can be indexed to the $(0$ $\left.\begin{array}{ll}0 & 1\end{array}\right),\left(\begin{array}{lll}1 & 0 & 0\end{array}\right),\left(\begin{array}{lll}0 & 0 & 2\end{array}\right),\left(\begin{array}{lll}1 & 0 & 1\end{array}\right),\left(\begin{array}{lll}0 & 0 & 3\end{array}\right),\left(\begin{array}{lll}1 & 1 & 0\end{array}\right)$ and (lll 111$)$ crystal planes of $\mathrm{SnS}_{2}$ hexagonal phase. (JCPDS Card no.89-2358). Similarly, the characteristic Bragg diffraction peaks for pristine $\mathrm{Sn}_{3} \mathrm{O}_{4}$ NPs were detected at $2 \theta=26.9^{\circ}, 32.1^{\circ}, 37.0^{\circ}$, and $51.7^{\circ}$ (Fig.1), which were

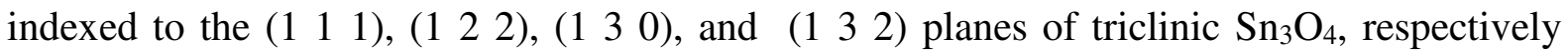
(JCPDS Card No.- 16- 0737). The XRD pattern of $0.05 \mathrm{Sn}_{3} \mathrm{O}_{4} / \mathrm{SnS}_{2}$ displayed characteristic peaks of pristine $\mathrm{SnS}_{2}$ along with few smaller intensity peaks corresponding to $\mathrm{Sn}_{3} \mathrm{O}_{4}$ (TableS1). The intensity of the diffraction peaks of $\mathrm{Sn}_{3} \mathrm{O}_{4}$ increased for the batches of $0.07 \mathrm{Sn}_{3} \mathrm{O}_{4} / \mathrm{SnS}_{2}$ and $0.10 \mathrm{Sn}_{3} \mathrm{O}_{4} / \mathrm{SnS}_{2}$, indicating gradual coverage of $\mathrm{Sn}_{3} \mathrm{O}_{4}$ nanoparticles on $\mathrm{SnS}_{2}$ surface. The detail information about crystallite sizes of the batches of $\mathrm{Sn}_{3} \mathrm{O}_{4} / \mathrm{SnS}_{2} \mathrm{NCs}$ and $\mathrm{SnS}_{2}$ were discuss in the supporting information (Section $\mathrm{S} 3$ ).

The morphology of $\mathrm{Sn}_{3} \mathrm{O}_{4} / \mathrm{SnS}_{2}$ NCs, along with their respective components e.g., $\mathrm{SnS}_{2}$ nanoparticles and $\mathrm{Sn}_{3} \mathrm{O}_{4}$ nanoflakes were analysed by electron microscopy (given as Supporting Information, Fig. S1). The FE-SEM image of pure $\mathrm{SnS}_{2}$ completely composed of clusters of nanoparticles with diameters in the range of 80-100 nm (Fig S1a). $\mathrm{Sn}_{3} \mathrm{O}_{4}$ was composed of relatively smooth irregular nanoflakes of size ranging in between 100-400 nm long and thickness about $10 \mathrm{~nm}$ (Fig S1b). The FE-SEM image of $0.07 \mathrm{Sn}_{3} \mathrm{O}_{4} / \mathrm{SnS}_{2} \mathrm{NCs}$ 
mostly revealed nanoclusters of $\mathrm{SnS}_{2}$, which is the major component in the nanocomposites, along with distribution of irregualar shaped nanoflakes of $\mathrm{Sn}_{3} \mathrm{O}_{4}$ (Fig S1c-d). The energy dispersive X-ray (EDX) spectrum of $0.07 \mathrm{Sn}_{3} \mathrm{O}_{4} / \mathrm{SnS}_{2} \mathrm{NCs}$ revealed the characteristic X-rays of Sn, S, and O. (Fig S1e), which indicated about formation of heterostructures of $\mathrm{Sn}_{3} \mathrm{O}_{4} / \mathrm{SnS}_{2}$. The morphology of the batch of $0.07 \mathrm{Sn}_{3} \mathrm{O}_{4} / \mathrm{SnS}_{2} \mathrm{NCs}$ was better revealed from the transmission electron microscopy (TEM) images. Here both nanoclusters of $\mathrm{SnS}_{2}$ and irregular shaped $\mathrm{Sn}_{3} \mathrm{O}_{4}$ nanoflakes could be observed corresponding to formation of $\mathrm{Sn}_{3} \mathrm{O}_{4} / \mathrm{SnS}_{2}$ nanocomposites (Fig. 2a). The $\mathrm{SnS}_{2}$ nanoclusters were 80-100 $\mathrm{nm}$ long and the sizes of $\mathrm{Sn}_{3} \mathrm{O}_{4}$ were in the range of $50-70 \mathrm{~nm}$ long and about 10 to $15 \mathrm{~nm}$ in width. The formation of heterostructures of $\mathrm{Sn}_{3} \mathrm{O}_{4} / \mathrm{SnS}_{2}$ is evident from the higher resolution TEM image which revealed heterojunction of $\mathrm{SnS}_{2}$ nanoclusterss and the irregular shaped $\mathrm{Sn}_{3} \mathrm{O}_{4}$ nanoflakes (Fig. 2b). The crystalline nature of $\mathrm{Sn}_{3} \mathrm{O}_{4} / \mathrm{SnS}_{2} \mathrm{NCs}$ is revealed from the lattice fringes with corresponded to binary materials with interatomic layer spacing of $0.314 \mathrm{~nm}$ and $0.330 \mathrm{~nm}$ (Fig. 2c). They correspond to the $\left(\begin{array}{lll}1 & 0 & 0\end{array}\right)$ lattice plane of hexagonal $\mathrm{SnS}_{2}$ and $\left(\begin{array}{lll}1 & 1 & 1\end{array}\right)$ plane of triclinic $\mathrm{Sn}_{3} \mathrm{O}_{4}$, respectively. The selected area electron diffraction (SAED) pattern confirmed the strong interference patterns due to polycrystalline nature of $\mathrm{Sn}_{3} \mathrm{O}_{4} / \mathrm{SnS}_{2} \mathrm{NCs}$ (Fig. 2d). The results of XRD, FESEM and TEM confirmed formation of $\mathrm{Sn}_{3} \mathrm{O}_{4} / \mathrm{SnS}_{2}$ heterostructure.

The proposed structure of $0.07 \mathrm{Sn}_{3} \mathrm{O}_{4} / \mathrm{SnS}_{2}$ was further corroborated by compositional analysis of tin (Sn), oxygen (O) and sulphur elements by XPS measurement (Fig. 3a). The binding energy peaks of Sn 3d shows two peaks at $486.88 \mathrm{eV}$ and $495.29 \mathrm{eV}$, which are assigned to $\mathrm{Sn} 3 \mathrm{~d}_{5 / 2}$ and $\mathrm{Sn} 3 \mathrm{~d}_{3 / 2}$, respectively, suggesting the presence of $\mathrm{Sn}^{4+}$ in $0.07 \mathrm{Sn}_{3} \mathrm{O}_{4} / \mathrm{SnS}_{2}$ (Fig. 3b).The binding energy peaks of $\mathrm{S} 2 \mathrm{p}$ displays a two strong peak at $161.72 \mathrm{eV}$ and $162.85 \mathrm{eV}$ corresponding to $\mathrm{S} 2 \mathrm{p}_{3 / 2}$ and $\mathrm{S} 2 \mathrm{p}_{1 / 2}$, respectively, which was attributed to the $\mathrm{S}^{2-}$ state (Fig. 3c). The O1s binding energy peak is deconvoluted into two 
peaks at $532.03 \mathrm{eV}$ and $531.13 \mathrm{eV}$ (Fig. 3d). The peaks corresponded to O- $\mathrm{Sn}^{4+}$ bond and O$\mathrm{Sn}^{2+}$, respectively, which are relevant to the proposed structural constituent of $0.07 \mathrm{Sn}_{3} \mathrm{O}_{4} / \mathrm{SnS}_{2} \mathrm{NCs}$. Therefore, the XPS results are consistent with the XRD and HRTEM findings shown above. This further provides more evidence that the obtained $0.07 \mathrm{Sn}_{3} \mathrm{O}_{4} / \mathrm{SnS}_{2}$ composite consists of $\mathrm{SnS}_{2}$ and $\mathrm{Sn}_{3} \mathrm{O}_{4}$.

The specific surface area of pristine $\mathrm{SnS}_{2}$ and $0.07 \mathrm{Sn}_{3} \mathrm{O}_{4} / \mathrm{SnS}_{2} \mathrm{NCs}$ were analysed by $\mathrm{N}_{2}$ adsorption-desorption isotherms and information about its porous nature was obtained from the BJH pore size distribution plot (Table S2). The BET plot of pure $\mathrm{SnS}_{2}$ and $0.07 \mathrm{Sn}_{3} \mathrm{O}_{4} / \mathrm{SnS}_{2} \mathrm{NCs}$ revealed type-IV isotherm (Fig. 4) and the corresponding BET surface area was determined as $55.06 \mathrm{~m}^{2} \mathrm{~g}^{-1}$ and $60.44 \mathrm{~m}^{2} \mathrm{~g}^{-1}$, respectively. The growth of $\mathrm{Sn}_{3} \mathrm{O}_{4}$ nanoflakes on the surface of the $\mathrm{SnS}_{2}$ surface increased the surface areas and the pore volume of the $0.07 \mathrm{Sn}_{3} \mathrm{O}_{4} / \mathrm{SnS}_{2}$ composites (Table $\mathrm{S} 2$ ). A narrow pore size distribution between 2-4 $\mathrm{nm}$ is obtained (inset of Fig. 4), which suggested mesoporous nature of the $0.07 \mathrm{Sn}_{3} \mathrm{O}_{4} / \mathrm{SnS}_{2}$ NCs. The mesoporous nature is also corroborated from the Type-IV isotherm plot (Peng et al. 2015). The high surface area and mesoporous structures of the $0.07 \mathrm{Sn}_{3} \mathrm{O}_{4} / \mathrm{SnS}_{2}$ composites, which is favourable for better interaction with pollutant molecules for adsorption and photocatalytic degradation. absorbance in the UV and visible light region (Fig. S2), whereas the $\mathrm{SnS}_{2}$ nanoclusers absorb only in the visible region (Fig. S2). The diffused reflectance spectra were converted to absorption spectra using conventional Kubelka-Munk function (Kortüm 1969), and the optical band gap was determined from Tauc plot given as, (Tauc et al. 1966)

$(\alpha h v)^{1 / \mathrm{n}}=A\left(h v-E_{\mathrm{g}}\right)$. 
In this equation $\alpha, h, v$ and $A$ refers to the absorption coefficient, Planck's constant, incident light frequency and proportionality constant, respectively. The value of ' $n$ ' is considered according to the nature of electronic transition, i.e. $n=1 / 2$ for direct transition and $n=2$ for indirect transition. The Tauc's plots of $0.05 \mathrm{Sn}_{3} \mathrm{O}_{4} / \mathrm{SnS}_{2} \quad \mathrm{NCs}, 0.07 \mathrm{Sn}_{3} \mathrm{O}_{4} / \mathrm{SnS}_{2} \quad \mathrm{NCs}$, $0.10 \mathrm{Sn}_{3} \mathrm{O}_{4} / \mathrm{SnS}_{2} \mathrm{NCs}$ and $\mathrm{SnS}_{2}$ nanoclusters are given in Fig. 5. The band gap of these materials were estimated by extrapolating the linear part of the respective Tauc plots to $(\alpha h v)^{2}$ $251=0$, as shown in Fig. 5 and by assuming the phenomenon of direct transition. The band gap of $0.05 \mathrm{Sn}_{3} \mathrm{O}_{4} / \mathrm{SnS}_{2} \mathrm{NCs}, 0.07 \mathrm{Sn}_{3} \mathrm{O}_{4} / \mathrm{SnS}_{2} \mathrm{NCs}$, and $0.10 \mathrm{Sn}_{3} \mathrm{O}_{4} / \mathrm{SnS}_{2} \mathrm{NCs}$ were determined to be $2.23 \mathrm{eV}, 2.24 \mathrm{eV}$ and $2.25 \mathrm{eV}$, respectively, which were similar to that of $\mathrm{SnS}_{2}$ nanoclusters $(\mathrm{Eg}=2.20 \mathrm{eV})$.

\section{Photocatalytic performance}

The photocatalytic reduction of $\mathrm{Cr}$ (VI) $(50 \mathrm{mg} / \mathrm{L})$ by the batches of $\mathrm{Sn}_{3} \mathrm{O}_{4} / \mathrm{SnS}_{2}$ nanocomposites (e.g., $0.05 \mathrm{Sn}_{3} \mathrm{O}_{4} / \mathrm{SnS}_{2} \mathrm{NCs}, 0.07 \mathrm{Sn}_{3} \mathrm{O}_{4} / \mathrm{SnS}_{2} \mathrm{NCs}$, and $0.10 \mathrm{Sn}_{3} \mathrm{O}_{4} / \mathrm{SnS}_{2} \mathrm{NCs}$ ) and those by the individual components, e.g., $\mathrm{SnS}_{2}$ nanoclusters and $\mathrm{Sn}_{3} \mathrm{O}_{4}$ nanoflakes are given as a plot of $C_{\mathrm{t}} / C_{0}$ versus time (Fig. 6a). Here $C_{0}$ and $C_{\mathrm{t}}$ are the initial concentration and concentration of $\mathrm{Cr}$ (VI) after a definite time of sunlight exposure. The decrease in the concentration of $\mathrm{Cr}$ (VI) due to adsorption on the respective photocatalysts was first determined from the dark experiment. About $40 \%$ of $\mathrm{Cr}$ (VI) was adsorbed on the batches of nanocomposites (i.e., $0.05 \mathrm{Sn}_{3} \mathrm{O}_{4} / \mathrm{SnS}_{2} \mathrm{NCs}, 0.07 \mathrm{Sn}_{3} \mathrm{O}_{4} / \mathrm{SnS}_{2} \mathrm{NCs}$, and $0.10 \mathrm{Sn}_{3} \mathrm{O}_{4} / \mathrm{SnS}_{2} \mathrm{NCs}$ ) while about $14 \%$ of $\mathrm{Cr}(\mathrm{VI})$ was adsorbed on $\mathrm{SnS}_{2}$ nanoclusters and $\mathrm{Sn}_{3} \mathrm{O}_{4}$ nanoflakes (Fig. 6a). The higher adsorption of $\mathrm{Cr}$ (VI) is primarily attributable to larger surface area and more favourable pore volume in $\mathrm{Sn}_{3} \mathrm{O}_{4} / \mathrm{SnS}_{2} \mathrm{NCs}$ (i.e., $60.44 \mathrm{~m}^{2} \mathrm{~g}^{-1}$ ) as compared to $55.06 \mathrm{~m}^{2} \mathrm{~g}^{-1}$ for pristine $\mathrm{SnS}_{2}$ nanoclusters. As $\mathrm{Sn}_{3} \mathrm{O}_{4}$ fraction was very less in the nanocomposites so its comparison was not done. The control experiment indicates that the self-decomposition of $\mathrm{Cr}$ (VI) is almost negligible whereas $\mathrm{Sn}_{3} \mathrm{O}_{4}$ shows poor photocatalytic reduction activity after 60 
min sunlight irradiation. All the batches of $\mathrm{Sn}_{3} \mathrm{O}_{4} / \mathrm{SnS}_{2}$ nanocomposites clearly displayed significantly higher photocatalytic reduction activity than that of pure $\mathrm{SnS}_{2}$ after the $60 \mathrm{~min}$ sunlight exposure, which indicates that $\mathrm{Sn}_{3} \mathrm{O}_{4}$ plays an important role in the enhancement of $\mathrm{Cr}$ (VI) reduction. The $0.07 \mathrm{Sn}_{3} \mathrm{O}_{4} / \mathrm{SnS}_{2} \mathrm{NCs}$ manifested the highest photocatalytic activity (about $100 \%$ removal efficiency of $\mathrm{Cr}$ (VI) after 60 min sunlight irradiations), while only 66 $\%$ of $\mathrm{Cr}$ (VI) was reduced under same condition using $\mathrm{SnS}_{2}$ as photocatalyst. Furthermore, it may be remarked here that the photocatalytic reduction of $\mathrm{Cr}$ (VI) by $\mathrm{Sn}_{3} \mathrm{O}_{4} / \mathrm{SnS}_{2} \mathrm{NCs}$ are depend on the content of $\mathrm{Sn}_{3} \mathrm{O}_{4}$ in $\mathrm{Sn}_{3} \mathrm{O}_{4} / \mathrm{SnS}_{2}$ NCs. The photocatalytic reduction activity of $0.07 \mathrm{Sn}_{3} \mathrm{O}_{4} / \mathrm{SnS}_{2} \mathrm{NCs}$ reached the highest. However, $0.10 \mathrm{Sn}_{3} \mathrm{O}_{4} / \mathrm{SnS}_{2}$ NCs displayed a decrease in photocatalytic reduction activity, when the $\mathrm{Sn}_{3} \mathrm{O}_{4}$ content was further increased. The most possible reason for the decrease in photocatalytic reduction activity of $0.10 \mathrm{Sn}_{3} \mathrm{O}_{4} / \mathrm{SnS}_{2} \mathrm{NCs}$ was that the excess of $\mathrm{Sn}_{3} \mathrm{O}_{4}$ covering the active site of $\mathrm{Sn}_{3} \mathrm{O}_{4} / \mathrm{SnS}_{2}$ NCs, so the number of active sites were reduced. The increase in photocatalytic reduction activity of $0.07 \mathrm{Sn}_{3} \mathrm{O}_{4} / \mathrm{SnS}_{2}$ can be substantiated with the increase in surface area and pore volume (as observed in BET results, Table-S2), help in better absorptivity of the Cr (VI) molecules on the photocatalyst surface as well as formation of heterojunctions in the $\mathrm{Sn}_{3} \mathrm{O}_{4} / \mathrm{SnS}_{2}$ NCs significantly assist in interfacial charge separation of the photoexcited excitons during the course of photocatalytic reduction process.

The photocatalytic reduction mechanism was studied by fitting the time dependent $\mathrm{Cr}$ (VI) dreduction data with pseudo first-order kinetics model. The first order kinetics model is given as:

$$
\ln \left(C_{0} / C_{t}\right)=k_{1} t
$$

where, $C_{0}$ and $C_{\mathrm{t}}$ are already defined, $k_{1}\left(\mathrm{~min}^{-1}\right)$ is the first order photocatalytic reduction rate constant for $\mathrm{Cr}$ (VI). (Table-1) The corresponding photocatalytic reduction rate of $0.07 \mathrm{Sn}_{3} \mathrm{O}_{4} / \mathrm{SnS}_{2}\left(k_{1}=0.066 \mathrm{~min}^{-1}\right)$ is 5.5 times than pristine $\mathrm{SnS}_{2}\left(k=0.012 \mathrm{~min}^{-1}\right)$ and 66 
times with respect to $\mathrm{Sn}_{3} \mathrm{O}_{4}\left(\mathrm{k}=0.0010 \mathrm{~min}^{-1}\right.$, Fig.6b). The corresponding UV-vis absorption spectra recorded during the photocatalytic reduction of $\mathrm{Cr}$ (VI) solution by the optimized $0.07 \mathrm{Sn}_{3} \mathrm{O}_{4} / \mathrm{SnS}_{2}$ photocatalyst under sunlight irradiation is given as Supporting Information (Fig.S3a). It can be seen that the intensity of the characteristic absorption peak of $\mathrm{Cr}$ (VI) at about $540 \mathrm{~nm}$ decreased gradually and it nearly disappeared after $60 \mathrm{~min}$. Additionally, the solution after the photocatalytic reduction of $\mathrm{Cr}$ (VI) over $0.07 \mathrm{Sn}_{3} \mathrm{O}_{4} / \mathrm{SnS}_{2}$ sample was detected using ICP-OES with $\mathrm{Cr}$ (VI) standard curve to confirm the content of $\mathrm{Cr}$ ions in solution (Fig.S4). The results show that the contents of $\mathrm{Cr}$ ions are $0.037 \mathrm{mg} / \mathrm{L}$ for sunlight light-driven photocatalytic reduction of $\mathrm{Cr}(\mathrm{VI})$.

\section{Effects of pH on photocatalytic reduction of $\mathrm{Cr}(\mathrm{VI})$}

The $\mathrm{Cr}$ (VI) removal efficiency continuously decreased with the increasing $\mathrm{pH}$ of the 306 initial solution. When the $\mathrm{pH}$ was increased to 10.50 , the total removal rate of $\mathrm{Cr}$ (VI) was considerably reduced to $14.91 \%$. These results are also presented in the corresponding UVvis absorption spectra (Fig.S5). The higher reduction potential at acidic conditions indicates that the reaction is more feasible under acidic conditions. The reasons for the above results are as follows. First, $\mathrm{Cr}$ (VI) exists mainly as dichromate anion $\left(\mathrm{Cr}_{2} \mathrm{O}_{7}{ }^{2-}\right)$ and hydrogen chromate ion $\left(\mathrm{HCrO}_{4}^{-}\right)$under acidic conditions and as chromate ion $\left(\mathrm{CrO}_{4}{ }^{2-}\right)$ under alkaline conditions. Secondly, under acidic condition, the reduction potential $\left(\mathrm{E} \mathrm{Cr}_{2} \mathrm{O}_{7}{ }^{2-} / \mathrm{Cr}^{3+}\right)$ is 1.23 $\mathrm{V}$ vs $\mathrm{NHE}$ and $\left(\mathrm{E}^{\mathrm{HCrO}}{ }_{4} / \mathrm{Cr}^{3+}\right)$ is $1.35 \mathrm{~V}$ vs $\mathrm{NHE}$ which is much more positive then the

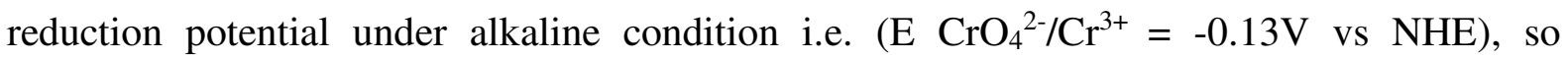
tendency to reduce from $\mathrm{Cr}^{6+}$ to $\mathrm{Cr}^{3+}$ under acidic condition is much more easier then alkaline condition (Equation 2-4). The reactions that occur in acidic and alkaline solutions are:

Cr reduction under acidic medium

$$
\begin{aligned}
& \mathrm{Cr}_{2} \mathrm{O}_{7}^{2-}+14 \mathrm{H}^{+}+6 \mathrm{e}^{-} \longrightarrow 2 \mathrm{Cr}^{3+}+7 \mathrm{H}_{2} \mathrm{O} \\
& \mathrm{HCrO}_{4}^{-}+7 \mathrm{H}^{+}+3 \mathrm{e}^{-} \longrightarrow 2 \mathrm{Cr}^{3+}+7 \mathrm{H}_{2} \mathrm{O}
\end{aligned}
$$




$$
\mathrm{CrO}_{4}{ }^{2-}+4 \mathrm{H}_{2} \mathrm{O}+3 \mathrm{e}^{-} \longrightarrow \mathrm{Cr}(\mathrm{OH})_{3}+5 \mathrm{OH}
$$

Overall, the photocatalytic reduction of $\mathrm{Cr}(\mathrm{VI})$ consumes $\mathrm{H}^{+}$, and acidic conditions are more favorable for $\mathrm{Cr}(\mathrm{VI})$ reduction then basic one.

\section{7}

\section{Photocatalytic degradation of methylene blue (MB) dye}

The photocatalytic degradation of another class of pollutants with different molecular structure, i.e., methylene blue (MB, $20 \mathrm{mg} / \mathrm{L})$ was investigated by all the batches of $0.07 \mathrm{Sn}_{3} \mathrm{O}_{4} / \mathrm{SnS}_{2}$ NCs and those by $\mathrm{Sn}_{3} \mathrm{O}_{4}$ and $\mathrm{SnS}_{2}$ NCs. The photocatalytic degradation profile including the initial dark experiments for MB by all the batches of photocatalysts under study are given in Fig. $6 \mathrm{c}$. The $0.07 \mathrm{Sn}_{3} \mathrm{O}_{4} / \mathrm{SnS}_{2}$ nanocomposite shows $36 \%$ adsorption of $\mathrm{MB}$ dye in the dark condition, whereas $\mathrm{Sn}_{3} \mathrm{O}_{4}$ and $\mathrm{SnS}_{2}$ shows $11 \%$ and $13 \%$ adsorption respectively, indicating that high adsorption capacity favors in the photocatalytic process. As expected, the sunlight mediated MB degradation was significantly higher for the batches of $\mathrm{Sn}_{3} \mathrm{O}_{4} / \mathrm{SnS}_{2} \mathrm{NCs}$ as compared to those by $\mathrm{Sn}_{3} \mathrm{O}_{4}$ and $\mathrm{SnS}_{2}$. The best result, i.e., $99.6 \%$ degradation of $\mathrm{MB}$ was recorded for the batch treated with $0.07 \mathrm{Sn}_{3} \mathrm{O}_{4} / \mathrm{SnS}_{2} \mathrm{NCs}$. The degradation followed pseudo-first order kinetic model (Fig. 6d). The corresponding photocatalytic degradation rate for $0.07 \mathrm{Sn}_{3} \mathrm{O}_{4} / \mathrm{SnS}_{2}\left(k_{2}=0.043 \mathrm{~min}^{-1}\right)$, which is 5.37 times higher than the pristine $\mathrm{SnS}_{2}\left(k=0.008 \mathrm{~min}^{-1}\right)$ and 10.75 times higher than $\mathrm{Sn}_{3} \mathrm{O}_{4}(k=0.004$ $\left.\min ^{-1}\right)$. The corresponding UV-vis absorption spectra recorded during the photocatalytic degradation of $\mathrm{MB}$ dye solution by the optimized $0.07 \mathrm{Sn}_{3} \mathrm{O}_{4} / \mathrm{SnS}_{2}$ photocatalyst under 
intensity of the characteristic absorption peak of $\mathrm{MB}$ at about $665 \mathrm{~nm}$ decreased gradually and it nearly disappeared after $90 \mathrm{~min}$.

The degree of mineralization of $\mathrm{MB}$ dye was estimated from total organic content (TOC) in the respective residual solutions treated with $0.07 \mathrm{Sn}_{3} \mathrm{O}_{4} / \mathrm{SnS}_{2}$ NCs after photocatalytic degradation for 90 minutes sunlight exposure. Expectedly, these values were high then the TOC removal by pristine $\mathrm{SnS}_{2}$ and $\mathrm{Sn}_{3} \mathrm{O}_{4}$ (supporting information Fig. S6). The TOC values were $85.1 \%$ for $\mathrm{MB}$ dye, which corresponded to $99.6 \%$ degradation respectively. Similar trend on incomplete degradation from TOC results are also found in literature ( $\mathrm{Du}$ et al. 2021). It may be assumed that longer sunlight exposure could lead to complete mineralization of $\mathrm{MB}$ dye into $\mathrm{CO}_{2}$ and $\mathrm{H}_{2} \mathrm{O}$ by treating with the photocatalyst (Liu et al. 2020).

The pathways for photocatalytic degradation of MB were addressed by identifying the

radicals $(\cdot \mathrm{OH})$ facilitates demethylation of the organic compounds. The intermediate P1 is further demethylated and deaminized to form intermediate P2 $(\mathrm{m} / z=198)$, which was further oxidised to form intermediate P3 with $(\mathrm{m} / \mathrm{z}=214)$. The intermediates P3 finally oxidized to smaller molecule like $\mathrm{H}_{2} \mathrm{O}, \mathrm{CO}_{2}$. In the second pathway the sulphur-nitrogen conjugated system in the MB molecule is attacked by hydroxyl radical and degraded into intermediate P4 $(m / z=166)$. The intermediate P4 undergoes a series of demethylation to form intermediate P5 $(m / z=151)$ and P6 $(m / z=138)$, which was further oxidised to form intermediate P7 with 
form a smaller molecule i.e., P9 with $(m / z=97)$. In the end, small molecules P9 were further oxidized into carbon dioxide and water.

\section{Re-usability of photocatalyst}

The robustness of the as-synthesized batch of $0.07 \mathrm{Sn}_{3} \mathrm{O}_{4} / \mathrm{SnS}_{2} \mathrm{NCs}$ as photocatalyst was assessed from its chemical and photo-stability. The chemical stability was determined from metal ion leaching during the photocatalytic degradation process. The concentrations of leached metal ions of $\mathrm{Sn}$ at the end of five photocatalytic cycle, determined by calibration method using ICP-OES analysis, suggested minimal leaching (less than $7 \%$ ), as given in Supporting information Table S3). The concentrations of the leached metal ions in the reaction medium were determined from the respective calibration plots (Fig. S7). These results suggested excellent chemical stability of $0.07 \mathrm{Sn}_{3} \mathrm{O}_{4} / \mathrm{SnS}_{2} \mathrm{NCs}$ as photocatalyst.

The photo-stability of $0.07 \mathrm{Sn}_{3} \mathrm{O}_{4} / \mathrm{SnS}_{2} \quad \mathrm{NCs}$ as photocatalyst for $\mathrm{Cr}$ (VI) photoreduction is reflected from the re-usability of the photocatalyst for at least five successive cycles of photocatalytic reduction under optimized conditions. The photoreduction patterns are similar and the rate of photocatalytic reduction for all the five cycles are nearly similar (Fig. 7a). The stability of $0.07 \mathrm{Sn}_{3} \mathrm{O}_{4} / \mathrm{SnS}_{2} \mathrm{NCs}$ in the reaction medium was further confirmed from the XRD pattern of the used photocatalyst recovered after the $5^{\text {th }}$ cycle (Fig. 7b). The lattice parameters of the used photocatalyst are expectedly similar (Table S4, given as Supporting information). Furthermore, the morphology of the used $0.07 \mathrm{Sn}_{3} \mathrm{O}_{4} / \mathrm{SnS}_{2} \mathrm{NCs}$ recorded by FE-SEM also did not show any significant changes with respect to the pristine batch of photocatalyst (Fig. 7c).

\section{Photocatalytic reaction mechanism}

Broadly, photocatalytic reduction or degradation is initiated by absorption of photons of energy greater than the band gap of the photocatalyst followed by inhibition of charge carrier recombination (Sharma and Dutta 2018). Various factors are responsible for inhibition 
of charge carrier recombination, out of which the two significant ones are presence of defect states of energy lesser than that of the conduction band and mobility of charge carriers to the surface of the photocatalyst for ROS generation.

The photoluminescence spectra of pristine $\mathrm{Sn}_{3} \mathrm{O}_{4}$ nanoflakes $\mathrm{SnS}_{2}$ nanopartilces, $0.05 \mathrm{Sn}_{3} \mathrm{O}_{4} / \mathrm{SnS}_{2} \mathrm{NCs}, 0.07 \mathrm{Sn}_{3} \mathrm{O}_{4} / \mathrm{SnS}_{2} \mathrm{NCs}$, and $0.10 \mathrm{Sn}_{3} \mathrm{O}_{4} / \mathrm{SnS}_{2} \mathrm{NCs}$ revealed one radiative transitions, which corresponding to inter-band transition $(\sim 460 \mathrm{~nm})$ (Fig. 8a) (Sharma and Dutta 2018). Notably, the PL emission intensities for inter-band transition were significantly decreased for the batch of $\mathrm{Sn}_{3} \mathrm{O}_{4} / \mathrm{SnS}_{2} \mathrm{NCs}$ as compared to that of $\mathrm{Sn}_{3} \mathrm{O}_{4}$ and $\mathrm{SnS}_{2}$. The decrease in the PL intensity is consistent with increase in the rate of photocatalytic reduction and degradation. These results indicated that the charge carrier recombination is inhibited in $\mathrm{Sn}_{3} \mathrm{O}_{4} / \mathrm{SnS}_{2}$ and favoured interfacial charge transfer due to formation of heterojunction. These separated charge carriers have to move to the surface of the photocatalyst for generating reactive oxygen species (ROS) reacting with molecular oxygen and water. The mobility of the charge carriers in $\mathrm{SnS}_{2}$ and $\mathrm{Sn}_{3} \mathrm{O}_{4} / \mathrm{SnS}_{2} \mathrm{NCs}$ along with was studied from electrochemical impedance spectroscopy (EIS) measurements. The radius of the arc in the Nyquist plot for the electrode made of $0.07 \mathrm{Sn}_{3} \mathrm{O}_{4} / \mathrm{SnS}_{2}$ was smaller than the one made of $\mathrm{SnS}_{2}$ (Fig. 8b). Arc with smaller radius, i.e., $0.07 \mathrm{Sn}_{3} \mathrm{O}_{4} / \mathrm{SnS}_{2} \mathrm{NC}$, is attributed to lower the impedance or higher charge carrier transport ( $\mathrm{Li}$ et al. 2018b; Yi et al. 2019). Furthermore, the slope in the mid-frequency region corresponding to the Warburg region is more for $0.07 \mathrm{Sn}_{3} \mathrm{O}_{4} / \mathrm{SnS}_{2}$, which implied higher diffusion current than in pristine $\mathrm{SnS}_{2}$. These results are consistent with more favourable charge carrier transport in $0.07 \mathrm{Sn}_{3} \mathrm{O}_{4} / \mathrm{SnS}_{2}$ as compared to the pristine $\mathrm{SnS}_{2}$ and complimented with the higher photocatalytic activity exhibited by observed in $0.07 \mathrm{Sn}_{3} \mathrm{O}_{4} / \mathrm{SnS}_{2}$.

The interfacial charge transfer in a heterogeneous photocatalyst would depend on favourable configuration of conduction band and valence band energies in the photocatalyst. 
Empirically, the minimum energy of conduction band $\left(\mathrm{E}_{\mathrm{CB}}\right)$ and the maximum energy of the valence band $\left(\mathrm{E}_{\mathrm{VB}}\right)$ were calculated by using the following expressions: (Reddy et al. 1998)

$$
\begin{aligned}
& E_{C B}=\chi\left(\mathrm{A}_{\mathrm{a}} \mathrm{B}_{\mathrm{b}}\right)-1 / 2 E_{g}+E_{o} \\
& E_{V B}=E_{C B}+E_{g}
\end{aligned}
$$

where, $E_{\mathrm{g}}$ is the band gap of $0.07 \mathrm{Sn}_{3} \mathrm{O}_{4} / \mathrm{SnS}_{2} \mathrm{NCs}, E_{\mathrm{CB}}$ is the potential of the conduction band, $E_{\mathrm{VB}}$ is the valence band potential, $E_{\mathrm{o}}$ is the scale factor taken as $-4.50 \mathrm{eV}$, i.e., the energy of free electrons on the normal hydrogen electrode (NHE scale). The parameter $\chi\left(\mathrm{A}_{\mathrm{a}} \mathrm{B}_{\mathrm{b}}\right)$ corresponds to the absolute electronegativity of a semiconductor material type $A_{a} B_{b}$, which is calculated as the geometric mean of the electronegativity of the constituent atoms. The electronegativity value for $\mathrm{Sn}_{3} \mathrm{O}_{4}$ and $\mathrm{SnS}_{2}$ are calculated to be 5.91 $\mathrm{eV}$ and $5.37 \mathrm{eV}$, respectively, which are consistent with literature (Gao et al. 2016; Li et al. 2018a). The $\mathrm{E}_{\mathrm{CB}}$ and $\mathrm{E}_{\mathrm{vB}}$ of $\mathrm{Sn}_{3} \mathrm{O}_{4}$ are deduced as $0.01 \mathrm{eV}$ and $2.81 \mathrm{eV}$, respectively. Similarly, the $\mathrm{E}_{\mathrm{CB}}$ and the $\mathrm{E}_{\mathrm{VB}}$ of $\mathrm{SnS}_{2}$ are $-0.11 \mathrm{eV}$ and $2.09 \mathrm{eV}$, respectively. Since the conduction band potential of $\mathrm{SnS}_{2}$ is more negative than that of $\mathrm{Sn}_{3} \mathrm{O}_{4}$, the photogenerated electrons in the conduction band of $\mathrm{SnS}_{2}$ will migrate to the conduction band of $\mathrm{Sn}_{3} \mathrm{O}_{4}$, according to the traditional separation process of electron-hole pairs (Luo et al. 2019). By this charge transfer mode, the accumulated electrons in the conduction band of $\mathrm{Sn}_{3} \mathrm{O}_{4}$ cannot reduce $\mathrm{O}_{2}$ into $\mathrm{O}_{2}{ }^{-} \cdot$ radicals because the conduction band potential of $\mathrm{Sn}_{3} \mathrm{O}_{4}$ is more positive than that of the $\mathrm{O}_{2}{ }^{-} \cdot \operatorname{radical}(-0.046 \mathrm{eV}$ vs N.H.E) (Li et al. 2018a). Thus, it is not favourable for producing the main reactive species $\mathrm{O}_{2}{ }^{-}$if transfer of photogenerated charge occurs by the traditional electron-hole transfer process. However, the results of this trapping experiments revealed that $\mathrm{O}_{2}{ }^{-}$play an important role in the organic pollutant degradation process. On the basis of the above results, a possible Z-scheme mechanism for $\mathrm{Cr}$ (VI) reduction and $\mathrm{MB}$ degradation using the $\mathrm{Sn}_{3} \mathrm{O}_{4} / \mathrm{SnS}_{2}$ heterojunction photocatalyst was proposed, as illustrated in scheme- $2 \mathrm{a}$ and $2 \mathrm{~b}$. Unlike the traditional model, the Z-scheme 
mechanism photocatalysts retain the stronger oxidation and reduction ability, which deeply contributed to the improvement of photocatalytic performance (Liu et al. 2018; Lin et al. 2021; Qiang et al. 2021). Under visible-light irradiation, both $\mathrm{SnS}_{2}$ and $\mathrm{Sn}_{3} \mathrm{O}_{4}$ can absorb visible light photons to produce photogenerated electrons and holes. In case $\mathrm{Cr}$ (VI) photoreduction (scheme-2a), the photogenerated electrons in conduction band of $\mathrm{Sn}_{3} \mathrm{O}_{4}\left(e_{C B}^{-}\right)$ would transfer to valence band of $\mathrm{SnS}_{2}$ to recombine instantly with the photogenerated holes $\left(h_{V B}^{+}\right)$, while the valence band holes of $\mathrm{Sn}_{3} \mathrm{O}_{4}$ incite the decomposition of water with the photo-oxidation reaction. On the other hand, the conduction band electrons of $\mathrm{SnS}_{2}$ could easily utilize for the reduction of $\mathrm{Cr}$ (VI) to $\mathrm{Cr}$ (III), as the potential of conduction band of $\mathrm{SnS}_{2}(-0.11 \mathrm{eV})$ is more negative than the potential required for $\mathrm{Cr}$ (VI) photoreduction $454\left(\mathrm{E}\left(\mathrm{Cr}^{6+} / \mathrm{Cr}^{3+}\right)=0.55 \mathrm{eV}\right.$ vs. NHE). The pathways of $\mathrm{Cr}(\mathrm{VI})$ reduction are depicted in Eqs. (79).

$\mathrm{SnS}_{2}+\mathrm{h} v \longrightarrow e_{C B}^{-}+h_{V B}^{+}$

$\mathrm{Cr}_{2} \mathrm{O}_{7}^{2-}+14 \mathrm{H}^{+}+6 \mathrm{e}^{-}$

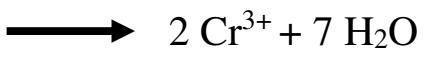

$2 \mathrm{H}_{2} \mathrm{O}+4 \mathrm{~h}^{+} \longrightarrow \mathrm{O}_{2}+4 \mathrm{H}^{+}$

The possible photocatalytic degradation mechanism of MB by $\mathrm{Sn}_{3} \mathrm{O}_{4} / \mathrm{SnS}_{2} \mathrm{NCs}$ is shown in (Scheme 2b). By analyzing the relative band gap positions of $\mathrm{E}_{\mathrm{CB}}$ and the $\mathrm{E}_{\mathrm{VB}}$ of $\mathrm{SnS}_{2}$ and $\mathrm{Sn}_{3} \mathrm{O}_{4}$, it can be found that the thermodynamic driving force of $\mathrm{e}^{-}$in conduction band of $\mathrm{SnS}_{2}$ is enough to reduce the adsorbed oxygen to generate $\mathrm{O}_{2}{ }^{-} \cdot\left(\mathrm{E}\left(\mathrm{O}_{2} / \mathrm{O}_{2}{ }^{-}{ }^{-}\right)=-0.046 \mathrm{eV}\right.$ vs. NHE). Meanwhile, the lower valence band potentials of $\mathrm{Sn}_{3} \mathrm{O}_{4}(2.81 \mathrm{eV})$ instead of $\mathrm{SnS}_{2}$ $(2.09 \mathrm{eV})$ can oxidize $\mathrm{OH}^{-}$to $\mathrm{OH}^{*}$ owing to the standard redox potential of $\mathrm{OH}^{*} / \mathrm{OH}^{-}$with 2.3 $\mathrm{eV}$. Therefore, it is clear that in this heterojunction system, $\mathrm{O}_{2}{ }^{-} \cdot$ and. $\mathrm{OH}$ are the mainstream active sites who truly matter in this photocatalytic degradation reaction.

467 This is well supported by the radical trapping studies (Fig. 9c), and the photogenerated charge carrier transfer process can be described as follows: 
$\mathrm{SnS}_{2}\left(e_{C B}^{-}+h_{V B}^{+}\right)+\mathrm{Sn}_{3} \mathrm{O}_{4}\left(e_{C B}^{-}+h_{V B}^{+}\right)$

$\mathrm{SnS}_{2}\left(e_{C B}^{-}\right)+\mathrm{Sn}_{3} \mathrm{O}_{4}\left(h_{V B}^{+}\right)$

$472 \mathrm{SnS}_{2}\left(h_{V B}^{+}\right)+\mathrm{Sn}_{3} \mathrm{O}_{4}\left(e_{C B}^{-}\right) \longrightarrow$ Recombination

$473 \mathrm{Sn}_{3} \mathrm{O}_{4}\left(h_{V B}^{+}\right)+\mathrm{OH}^{-} \longrightarrow \mathrm{OH}^{\bullet}+\mathrm{H}_{2} \mathrm{O}$

$\mathrm{SnS}_{2}\left(e_{C B}^{-}\right)+\mathrm{O}_{2} \longrightarrow \mathrm{SnS}_{2}+\mathrm{O}_{2}^{-}$

$\mathrm{O}_{2}{ }^{-}+$dye ${ }_{(\mathrm{aq})} \longrightarrow \mathrm{CO}_{2}+\mathrm{H}_{2} \mathrm{O}$

$\mathrm{OH}^{\bullet}+$ dye ${ }_{(\mathrm{aq})} \longrightarrow \mathrm{CO}_{2}+\mathrm{H}_{2} \mathrm{O}$

477 Consequently conclusion can be drawn that the photo-degradation by $\mathrm{Sn}_{3} \mathrm{O}_{4} / \mathrm{SnS}_{2}$

478

479

480

481

482

483

484

485

486

487

488

489

490

491

492

493

heterojunctions followed a direct Z-scheme mechanism, which not only promotes the separation efficiency of photogenerated electrons and holes but also shows a strong redox ability for antibiotic degradation.

\section{Reactive oxygen species (ROS) scavenging studies}

The influence of in-situ generated ROS in the reaction medium towards degradation of MB has been explored from some of the specific ROS scavenging action. The discussion in the previous section strongly indicated the role of superoxide radicals $\left(\mathrm{O}_{2}^{-}{ }^{-}\right)$towards photocatalytic degradation of $\mathrm{MB}$ by the optimum performing batch of $0.07 \mathrm{Sn}_{3} \mathrm{O}_{4} / \mathrm{SnS}_{2}$. In this pursuit, the hydroxide radicals $(. \mathrm{OH})$ are expected to play important role. Apart from this, generation of superoxide radicals $\left(\mathrm{O}_{2}{ }^{-}\right)$is relevant when photoexcited electrons are involved during photocatalytic process. In view of this photocatalytic degradation of MB by $0.07 \mathrm{Sn}_{3} \mathrm{O}_{4} / \mathrm{SnS}_{2} \mathrm{NCs}$ was monitored under optimized conditions in the presence of specific ROS scavengers, e.g. isopropyl alcohol (IPA, $1 \mathrm{mM}$ ) for scavenging $\mathrm{OH}^{\bullet}$ radicals (Sharma et al. 2017); ammonium oxalate (AO, $1 \mathrm{mM})$ for scavenging $\mathrm{h}^{+}$(Sharma and Dutta 2015); and chloroform (1 mM) for scavenging $\mathrm{O}_{2}^{-}{ }^{-}$(Mukherjee et al. 2021) radical, respectively. The ROS scavenging action was evident from the decrease in the rate of photocatalytic 
degradation of MB (Fig. 8c). The most significant decrease in the rate of photocatalytic

495

496

497

498

499

500

501

502

503

504

505

506

507

508

509

510

511

512

513

514

515

516

517

518 degradation of MB was observed for the batch treated with chloroform, i.e., super oxide radical scavenger (Table S5). This strongly suggested that the super oxide radical played very important role in the photocatalytic degradation of $\mathrm{MB}$ by $0.07 \mathrm{Sn}_{3} \mathrm{O}_{4} / \mathrm{SnS}_{2}$ photocatalyst. Besides, the decrease in the rate of photocatalytic degradation of $\mathrm{MB}$ by $0.07 \mathrm{Sn}_{3} \mathrm{O}_{4} / \mathrm{SnS}_{2}$ in the presence of isopropyl alcohol $\left(\mathrm{OH}^{\bullet}\right.$ radicals scavenger $)$ suggested that the photoexcited holes were also involved in generating ROS in the reaction medium. The ROS scavenging studies complimented the PL results of $0.07 \mathrm{Sn}_{3} \mathrm{O}_{4} / \mathrm{SnS}_{2}$ regarding predominant generation of super oxide radicals due to inhibition photoexcited charge carriers for the batch of $0.07 \mathrm{Sn}_{3} \mathrm{O}_{4} / \mathrm{SnS}_{2} \mathrm{NC}$ and consequential enhanced photocatalytic degradation of MB.

It may be concluded that $\mathrm{Sn}_{3} \mathrm{O}_{4} / \mathrm{SnS}_{2}$ nanocomposites are excellent solar photocatalyst which can be used for photoreduction of $\mathrm{Cr}$ (VI) and degradation of $\mathrm{MB}$ without any exogenous oxidant, e.g., ozone or hydrogen peroxide. It also does not require any electricity for operation. Further studies needs to be done to check its efficiency in real time tertiary treatment in water treatment plants.

\section{Conclusion}

A novel photocatalyst, viz. $\mathrm{Sn}_{3} \mathrm{O}_{4} / \mathrm{SnS}_{2}$ nanocomposite has been synthesized by a simple two-step hydrothermal synthetic route, which exhibited enhanced photocatalytic activity than its constituents towards photoreduction of hexavalent chromium $\mathrm{Cr}$ (VI) and degradation of methylene blue (MB) under natural sunlight. The rate constant for photocatalytic reduction and degradation of $\mathrm{Cr}$ (VI) and $\mathrm{MB}$, respectively, by $0.07 \mathrm{Sn}_{3} \mathrm{O}_{4} / \mathrm{SnS}_{2}$ were about five times higher than that of $\mathrm{SnS}_{2}$ photocatalyst. The improved rate constant has been discussed in the light of separation of the photogenerated charge carriers owing to formation of a Z-scheme heterojunction and sustained release of reactive oxygen species in the reaction medium. The photocatalytic degradation mechanism has been 
addressed by analyzing the degradation product by UPLC-Q-ToF-MS and from total carbon content. The excellent chemical and photostability and re-usability of $\mathrm{Sn}_{3} \mathrm{O}_{4} / \mathrm{SnS}_{2}$ nanocomposite, makes it an efficient photocatalyst choice for the potential degradation of organic compounds in wastewater.

\section{Statements and Declarations}

Funding information Fund not available for this work.

Competing Interest The authors declare no competing interests

Ethics approval Not applicable

Consent to participate Not applicable

Consent for publication Not applicable

Authors contributions Gandharve Kumar contributed to the study conception and design and experiments. R.K. Dutta supervised the work and prepared the manuscript.

\section{References}

Barrera-Díaz CE, Lugo-Lugo V, Bilyeu B (2012) A review of chemical, electrochemical and biological methods for aqueous Cr (VI) reduction. J Hazard Mater 223-224:1-12. https://doi.org/10.1016/j.jhazmat.2012.04.054

Bethi B, Sonawane SH, Bhanvase BA, Gumfekar SP (2016) Nanomaterials-based advanced oxidation processes for wastewater treatment: A review. Chem Eng Process Process Intensif 109:178-189. https://doi.org/10.1016/j.cep.2016.08.016

Calvete MJF, Piccirillo G, Vinagreiro CS, Pereira MM (2019) Hybrid materials for heterogeneous photocatalytic degradation of antibiotics. Coord Chem Rev 395:63-85. https://doi.org/10.1016/j.ccr.2019.05.004

Coetzee JJ, Bansal N, Chirwa EMN (2020) Chromium in Environment, Its Toxic Effect from 
Das D, Dutta RK (2015) A novel method of synthesis of small band gap SnS nanorods and its efficient photocatalytic dye degradation. J Colloid Interface Sci 457:339-344. https://doi.org/10.1016/j.jcis.2015.07.002

Di T, Xu Q, Ho WK, et al (2019) Review on Metal Sulphide-based Z-scheme Photocatalysts. ChemCatChem 11:1394-1411. https://doi.org/10.1002/cctc.201802024

Du Z, Feng L, Guo Z, et al (2021) Ultrathin h-BN/Bi $2 \mathrm{MoO}_{6}$ heterojunction with synergetic effect for visible-light photocatalytic tetracycline degradation. J Colloid Interface Sci 589:545-555. https://doi.org/10.1016/j.jcis.2021.01.027

Fick J, Söderström H, Lindberg RH, et al (2009) Pharmaceuticals and personal care products in the environment contamination of surface, ground, and drinking water from pharmaceutical production. Environ Toxicol Chem 28:2522-2527

Gao X, Huang G, Gao H, et al (2016) Facile fabrication of $\mathrm{Bi}_{2} \mathrm{~S}_{3} / \mathrm{SnS}_{2}$ heterojunction photocatalysts with efficient photocatalytic activity under visible light. J Alloys Compd 674:98-108. https://doi.org/10.1016/j.jallcom.2016.03.031

Gusain R, Gupta K, Joshi P, Khatri OP (2019) Adsorptive removal and photocatalytic degradation of organic pollutants using metal oxides and their composites: A comprehensive review. Adv Colloid Interface Sci 272:102009. https://doi.org/10.1016/j.cis.2019.102009

Hafiane A, Lemordant D, Dhahbi M (2000) Removal of hexavalent chromium by nanofiltration. Desalination 130:305-312. https://doi.org/10.1016/S00119164(00)00094-1 
He C, Gu L, Xu Z, et al (2020) Cleaning chromium pollution in aquatic environments by bioremediation, photocatalytic remediation, electrochemical remediation and coupled remediation systems. Environ Chem Lett 18:561-576. https://doi.org/10.1007/s10311019-00960-3

Huang D, Li J, Zeng G, et al (2019) Facile construction of hierarchical flower-like Z-scheme $\mathrm{AgBr} / \mathrm{Bi}_{2} \mathrm{WO}_{6}$ photocatalysts for effective removal of tetracycline: Degradation

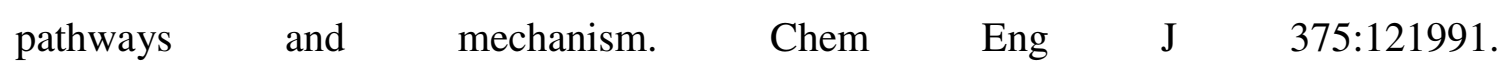
https://doi.org/10.1016/j.cej.2019.121991

Karimi-Maleh H, Ayati A, Ghanbari S, et al (2021) Recent advances in removal techniques of $\mathrm{Cr}$ (VI) toxic ion from aqueous solution: A comprehensive review. J Mol Liq 329:. https://doi.org/10.1016/j.molliq.2020.115062

Katheresan V, Kansedo J, Lau SY (2018) Efficiency of various recent wastewater dye removal methods: A review. J Environ Chem Eng 6:4676-4697. https://doi.org/10.1016/j.jece.2018.06.060

Khan NA, Ahmed S, Farooqi IH, et al (2020) Occurrence, sources and conventional treatment techniques for various antibiotics present in hospital wastewaters: A critical review. TrAC - Trends Anal Chem 129:. https://doi.org/10.1016/j.trac.2020.115921

Khatri A, Peerzada MH, Mohsin M, White M (2015) A review on developments in dyeing cotton fabrics with reactive dyes for reducing effluent pollution. J Clean Prod 87:50-57. https://doi.org/10.1016/j.jclepro.2014.09.017

Kortüm G (1969) Reflectance Spectroscopy, translated by JE Lohr

Li C, Yu S, Dong H, et al (2018a) Z-scheme mesoporous photocatalyst constructed by modification of $\mathrm{Sn}_{3} \mathrm{O}_{4}$ nanoclusters on $\mathrm{g}-\mathrm{C}_{3} \mathrm{~N}_{4}$ nanosheets with improved photocatalytic 
performance and mechanism insight. Appl Catal B Environ 238:284-293. https://doi.org/10.1016/j.apcatb.2018.07.049

591

592

593

594

595

596

597

598

599

600

601

602

603

604

605

606

607

608

609

610

611

Li H, Hu T, Zhang R, et al (2016) Preparation of solid-state Z-scheme $\mathrm{Bi}_{2} \mathrm{MoO}_{6} / \mathrm{MO}(\mathrm{MCu}$, $\mathrm{Co}_{3 / 4}$, or $\mathrm{Ni}$ ) heterojunctions with internal electric field-improved performance in photocatalysis.

Appl

Catal

B

Environ

188:313-323. https://doi.org/10.1016/j.apcatb.2016.02.015

Li Z, Meng X, Zhang Z (2018b) Few-layer MoS2 nanosheets-deposited on $\mathrm{Bi}_{2} \mathrm{MoO}_{6}$ microspheres: A Z-scheme visible-light photocatalyst with enhanced activity. Catal Today 315:67-78. https://doi.org/10.1016/j.cattod.2018.03.014

Lin Z, Zheng Y, Deng F, et al (2021) Target-directed design of dual-functional Z-scheme $\mathrm{AgIn}_{5} \mathrm{~S}_{8} / \mathrm{SnS}_{2}$ heterojunction for $\mathrm{Pb}$ (II) capture and photocatalytic reduction of $\mathrm{Cr}(\mathrm{VI})$ : Performance and mechanism insight. Sep Purif Technol 277:119430. https://doi.org/10.1016/j.seppur.2021.119430

Liu C, Lü H, Yu C, et al (2020) Novel $\mathrm{FeWO}_{4} / \mathrm{WO}_{3}$ nanoplate with p-n heterostructure and its enhanced mechanism for organic pollutants removal under visible-light illumination. J Environ Chem Eng 8:104044. https://doi.org/10.1016/j.jece.2020.104044

Liu Y, Geng P, Wang J, et al (2018) In-situ ion-exchange synthesis $\mathrm{Ag}_{2} \mathrm{~S}$ modified $\mathrm{SnS}_{2}$ nanosheets toward highly photocurrent response and photocatalytic activity. J Colloid Interface Sci 512:784-791. https://doi.org/10.1016/j.jcis.2017.10.112

Luo J, Li R, Chen Y, et al (2019) Rational design of Z-scheme $\mathrm{LaFeO}_{3} / \mathrm{SnS}_{2}$ hybrid with boosted visible light photocatalytic activity towards tetracycline degradation. Sep Purif Technol 210:417-430. https://doi.org/10.1016/j.seppur.2018.08.028

Mertz W (1993) Chromium in Human Nutrition: A Review. J Nutr 123:626-633. 
613

614

615

616

617

618

619

620

621

622

623

624

625

626

627

628

629

630

631

632

633

Mukherjee I, Cilamkoti V, Dutta RK (2021) Sunlight-driven photocatalytic degradation of ciprofloxacin by carbon dots embedded in $\mathrm{ZnO}$ nanostructures. ACS Appl Nano Mater. https://doi.org/10.1021/acsanm.1c00883

Narayani M, Shetty KV (2013) Chromium-resistant bacteria and their environmental condition for hexavalent chromium removal: A review. Crit Rev Environ Sci Technol 43:955-1009. https://doi.org/10.1080/10643389.2011.627022

Owlad M, Aroua MK, Daud WAW, Baroutian S (2009) Removal of hexavalent chromiumcontaminated water and wastewater: A review. Water Air Soil Pollut 200:59-77. https://doi.org/10.1007/s11270-008-9893-7

Peng Y, Chen QG, Wang D, et al (2015) Synthesis of one-dimensional $\mathrm{WO}_{3}-\mathrm{Bi}_{2} \mathrm{WO}_{6}$ heterojunctions with enhanced photocatalytic activity. CrystEngComm 17:569-576. https://doi.org/10.1039/c4ce01884b

Qiang T, Chen L, Xia Y, Qin X (2021) Dual modified $\mathrm{MoS}_{2} / \mathrm{SnS}_{2}$ photocatalyst with Zscheme heterojunction and vacancies defects to achieve a superior performance in $\mathrm{Cr}$ (VI) reduction and dyes degradation. J Clean Prod 291:125213. https://doi.org/10.1016/j.jclepro.2020.125213

Ramachandra T V., Jain R, Krishnadas G (2011) Hotspots of solar potential in India. Renew Sustain Energy Rev 15:3178-3186. https://doi.org/10.1016/j.rser.2011.04.007

Reddy RR, Nazeer Ahammed Y, Rama Gopal K, Raghuram D V. (1998) Optical electronegativity and refractive index of materials. Opt Mater (Amst) 10:95-100. https://doi.org/10.1016/S0925-3467(97)00171-7

Saadati F, Keramati N, Ghazi MM (2016) Influence of parameters on the photocatalytic 

degradation of tetracycline in wastewater: A review. Crit Rev Environ Sci Technol 46:757-782. https://doi.org/10.1080/10643389.2016.1159093

Sedman RM, Beaumont J, McDonald TA, et al (2006) Review of the evidence regarding the carcinogenicity of hexavalent chromium in drinking water. J Environ Sci Heal - Part C Environ Carcinog $\quad$ Ecotoxicol $\quad$ Rev $24: 155-182$. https://doi.org/10.1080/10590500600614337

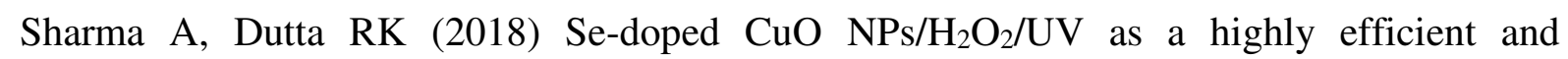
sustainable photo-Fenton catalytic system for enhanced degradation of 4-bromophenol. J Clean Prod 185:464-475. https://doi.org/10.1016/j.jclepro.2018.03.049

Sharma A, Dutta RK (2015) Studies on the drastic improvement of photocatalytic degradation of acid orange- 74 dye by TPPO capped $\mathrm{CuO}$ nanoparticles in tandem with suitable electron capturing agents. RSC Adv 5:43815-43823. https://doi.org/10.1039/c5ra04179a

Sharma A, Dutta RK, Roychowdhury A, et al (2017) Cobalt doped CuO nanoparticles as a highly efficient heterogeneous catalyst for reduction of 4-nitrophenol to 4-aminophenol. Appl Catal A Gen 543:257-265. https://doi.org/10.1016/j.apcata.2017.06.037

Sharma S, Bhattacharya A (2017) Drinking water contamination and treatment techniques. Appl Water Sci 7:1043-1067. https://doi.org/10.1007/s13201-016-0455-7

Singh R, Singh AP, Kumar S, et al (2019) Antibiotic resistance in major rivers in the world: A systematic review on occurrence, emergence, and management strategies. J Clean Prod 234:1484-1505. https://doi.org/10.1016/j.jclepro.2019.06.243

Tauc J, Grigorovici R, Vancu A (1966) Optical properties and electronic structure of amorphous germanium. Phys status solidi 15:627-637. 
659

660

661

662

663

664

665

666

667

668

669

670

671

672

673

674

675

676

677

678

679

680

Tumolo M, Ancona V, De Paola D, et al (2020) Chromium pollution in European water, sources, health risk, and remediation strategies: An overview. Int J Environ Res Public Health 17:1-25. https://doi.org/10.3390/ijerph17155438

Wang R, Zhu P, Liu M, et al (2021) Synthesis and characterization of magnetic $\mathrm{ZnFe}_{2} \mathrm{O}_{4} / \mathrm{Bi}^{0}{ }_{-}$ $\mathrm{Bi}_{2} \mathrm{MoO}_{6}$ with $\mathrm{Z}$-scheme heterojunction for antibiotics degradation under visible light. Sep Purif Technol 277:119339. https://doi.org/10.1016/j.seppur.2021.119339

Wang Y, Su Y, Fang W, et al (2020) $\mathrm{SnO}_{2} / \mathrm{SnS}_{2}$ nanocomposite anchored on nitrogen-doped RGO for improved photocatalytic reduction of aqueous Cr(VI). Powder Technol 363:337-348. https://doi.org/10.1016/j.powtec.2020.01.009

Wei Z, Liu J, Shangguan W (2020) A review on photocatalysis in antibiotic wastewater: Pollutant degradation and hydrogen production. Chinese J Catal 41:1440-1450. https://doi.org/10.1016/S1872-2067(19)63448-0

$\mathrm{Xu}$ L, Chen W qian, Ke S qiang, et al (2020) Construction of heterojunction $\mathrm{Bi} / \mathrm{Bi}_{5} \mathrm{O}_{7} \mathrm{I} / \mathrm{Sn}_{3} \mathrm{O}_{4}$ for efficient noble-metal-free Z-scheme photocatalytic H2 evolution. Chem Eng J 382:122810. https://doi.org/10.1016/j.cej.2019.122810

Yaseen DA, Scholz M (2019) Textile dye wastewater characteristics and constituents of synthetic effluents: a critical review. Springer Berlin Heidelberg

Yi J, Mo H, Zhang B, et al (2019) $\mathrm{CeO}_{2} / \mathrm{Bi}_{2} \mathrm{MoO}_{6}$ heterostructured microspheres with synergistic effect for accelerating photogenerated charge separation. Sep Purif Technol 211:474-480. https://doi.org/10.1016/j.seppur.2018.10.022

Zhang G, Chen D, Li N, et al (2019) Fabrication of $\mathrm{Bi}_{2} \mathrm{MoO}_{6} / \mathrm{ZnO}$ hierarchical heterostructures with enhanced visible-light photocatalytic activity. Appl Catal B 
682

683

684

685

686

687

688

689

690

691

692

693

694

695

696

697

698

699

700

701

702

Zhang $\mathrm{H}$, Bian $\mathrm{H}$, Zhang $\mathrm{H}$, et al (2020) Magnetic Separable $\mathrm{Bi}_{2} \mathrm{Fe}_{4} \mathrm{O}_{9} / \mathrm{Bi}_{2} \mathrm{MoO}_{6}$ Heterojunctions in Z-Scheme with Enhanced Visible-Light Photocatalytic Activity for Organic Pollutant Degradation. Catal Letters 150:2464-2473. https://doi.org/10.1007/s10562-020-03157-4

Zhao W, Feng Y, Huang H, et al (2019) A novel Z-scheme $\mathrm{Ag}_{3} \mathrm{VO}_{4} / \mathrm{BiVO}_{4}$ heterojunction photocatalyst: Study on the excellent photocatalytic performance and photocatalytic mechanism.

Appl

Catal

B

Environ 245:448-458. https://doi.org/10.1016/j.apcatb.2019.01.001

\section{$\underline{\text { Table captions }}$}

Table 1. Summary of the photocatalytic reduction of $\mathrm{Cr}$ (VI) and photocatalytic degradation of methylene blue experiments carried out under optimized condition, i.e. photocatalyst and sunlight.

\section{Figure Captions.}

\section{Figure Captions.}

Fig. 1 XRD patterns of the as-synthesized batches of $\mathrm{SnS}_{2}$ nanoparticles, $\mathrm{Sn}_{3} \mathrm{O}_{4}$ nanoflakes, $0.05 \mathrm{Sn}_{3} \mathrm{O}_{4} / \mathrm{SnS}_{2}$ nanocomposite, $0.07 \mathrm{Sn}_{3} \mathrm{O}_{4} / \mathrm{SnS}_{2}$ nanocomposite, and $0.10 \mathrm{Sn}_{3} \mathrm{O}_{4} / \mathrm{SnS}_{2}$ nanocomposite.

Fig. 2 Low resolution transmission electron microscopy images of $0.07 \mathrm{Sn}_{3} \mathrm{O}_{4} / \mathrm{SnS}_{2}$ (a-b); higher resolution transmission electron microscopy images of $0.07 \mathrm{Sn}_{3} \mathrm{O}_{4} / \mathrm{SnS}_{2}$ (c); (d) selected area electron diffraction pattern of $0.07 \mathrm{Sn}_{3} \mathrm{O}_{4} / \mathrm{SnS}_{2}$ 
703

704

705

706

707

708

709

710

711

712

713

714

715

716

717

718

719

720

721

722

723

724

725

726

727

Fig. 3 Binding energy spectra of $0.07 \mathrm{Sn}_{3} \mathrm{O}_{4} / \mathrm{SnS}_{2}$ nanocomposite obtained from $\mathrm{X}$-ray photoelectron spectroscopy measurements of (a) survey spectrum; (b) Sn 3d; (c) S 2p; and (d) O 1s.

Fig. $4 \mathrm{~N}_{2}$ adsorption- desorption isotherms of pristine $\mathrm{SnS}_{2}$ and $0.07 \mathrm{Sn}_{3} \mathrm{O}_{4} / \mathrm{SnS}_{2} \mathrm{NCs}$ (Inset represents the respective pore size distribution curves of pristine $\mathrm{SnS}_{2}$ and $0.07 \mathrm{Sn}_{3} \mathrm{O}_{4} / \mathrm{SnS}_{2}$ NCs).

Fig. 5 Tauc's plot of pristine $\mathrm{Sn}_{3} \mathrm{O}_{4}$, pristine $\mathrm{SnS}_{2}$, and $\mathrm{Sn}_{3} \mathrm{O}_{4} / \mathrm{SnS}_{2}$ composites.

Fig. 6 a) Dynamic curves of photocatalytic reduction of $\mathrm{Cr}(\mathrm{VI})$ by different photocatalysts under sunlight irradiation, b) pseudo first- order kinetic fitting of $\mathrm{Cr}$ (VI) reduction over different photocatalyst under sunlight irradiation, c) Dynamic curves of photocatalytic degradation of MB by different photocatalysts under sunlight irradiation, and d) pseudo firstorder kinetic fitting of $\mathrm{MB}$ degradation over different photocatalyst under sunlight irradiation, under sunlight.

Fig. 7 (a) Recyclability of the $0.07 \mathrm{Sn}_{3} \mathrm{O}_{4} / \mathrm{SnS}_{2} \mathrm{NCs}$ up to five photocatalytic reduction cycles;

(b) X-ray diffraction pattern and (c) scanning electron microscopy image of the recycled photocatalyst.

Fig. 8 a) Steady state room- temperature photoluminescence (PL) spectra, (b) electrochemical impedance spectra of $\mathrm{SnS}_{2}$ and $0.07 \mathrm{Sn}_{3} \mathrm{O}_{4} / \mathrm{SnS}_{2}$, and, (c) Effect of reactive oxygen species scavengers on photocatalytic reduction of $\mathrm{Cr}(\mathrm{VI})$ by $0.07 \mathrm{Sn}_{3} \mathrm{O}_{4} / \mathrm{SnS}_{2}$ nanocomposites under sunlight.

Scheme 1 Schematic diagram of proposed MB degradation pathway by $0.07 \mathrm{Sn}_{3} \mathrm{O}_{4} / \mathrm{SnS}_{2} \mathrm{NCS}$ along with MS spectra of possible intermediate of MB photodegradation by $0.07 \mathrm{Sn}_{3} \mathrm{O}_{4} / \mathrm{SnS}_{2}$.

Scheme 2. Possible photocatalytic mechanism of $\mathrm{Cr}$ (VI) (a) and $\mathrm{MB}$ (b) on $0.07 \mathrm{Sn}_{3} \mathrm{O}_{4} / \mathrm{SnS}_{2}$ nanocomposites 
Table 1

\begin{tabular}{|c|c|c|c|c|c|c|c|c|}
\hline \multirow[t]{2}{*}{ Sample name } & \multirow{2}{*}{$\begin{array}{c}\% \\
\text { adsorpti } \\
\text { on }\end{array}$} & \multirow[t]{2}{*}{$\begin{array}{c}\% \\
\text { Reduction }\end{array}$} & \multicolumn{2}{|c|}{$\begin{array}{l}1^{\text {st }} \text { order kinetics } \\
\text { Sunlight }(\operatorname{Cr}(\mathrm{VI}))\end{array}$} & \multirow{2}{*}{$\begin{array}{c}\% \\
\text { adsorptio } \\
\text { n }\end{array}$} & \multirow[t]{2}{*}{$\begin{array}{c}\% \\
\text { Degradation }\end{array}$} & \multicolumn{2}{|c|}{$\begin{array}{c}1^{\text {st }} \text { order kinetics } \\
\text { Sunlight }(\mathrm{MB})\end{array}$} \\
\hline & & & $\begin{array}{l}\text { Rate } \\
\text { constant } \\
\left(\text { min }^{-1}\right)\end{array}$ & $\mathbf{R}^{2}$ & & & $\begin{array}{l}\text { Rate constant } \\
\left(\text { min }^{-1}\right)\end{array}$ & $\mathbf{R}^{2}$ \\
\hline $0.10 \mathrm{Sn}_{3} \mathrm{O}_{4} / \mathrm{SnS}_{2}$ & $21 \%$ & $89 \%$ & 0.032 & 0.994 & $33 \%$ & $91 \%$ & 0.020 & 0.989 \\
\hline $0.05 \mathrm{Sn}_{3} \mathrm{O}_{4} / \mathrm{SnS}_{2}$ & $20 \%$ & $90 \%$ & 0.034 & 0.993 & $30 \%$ & $84 \%$ & 0.015 & 0.990 \\
\hline $\mathrm{SnS}_{2}$ & $14 \%$ & $66 \%$ & 0.012 & 0.995 & $13 \%$ & $58 \%$ & 0.008 & 0.991 \\
\hline $\mathrm{Sn}_{3} \mathrm{O}_{4}$ & $15 \%$ & $18 \%$ & 0.0010 & 0.974 & $11 \%$ & $39 \%$ & 0.004 & 0.970 \\
\hline Blank & NA & $10 \%$ & 0.002 & 0.983 & NA & $9 \%$ & 0.001 & 0.975 \\
\hline
\end{tabular}


Figures

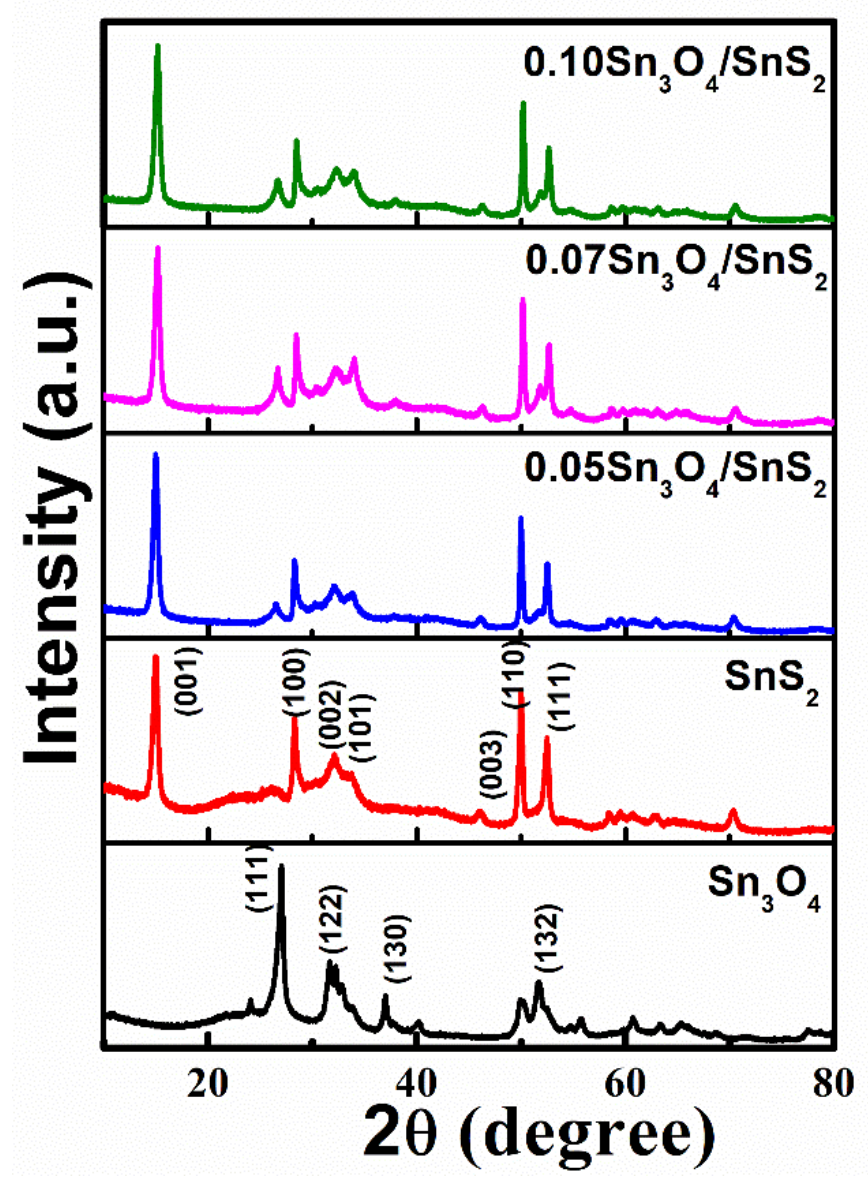

Fig. 1. 


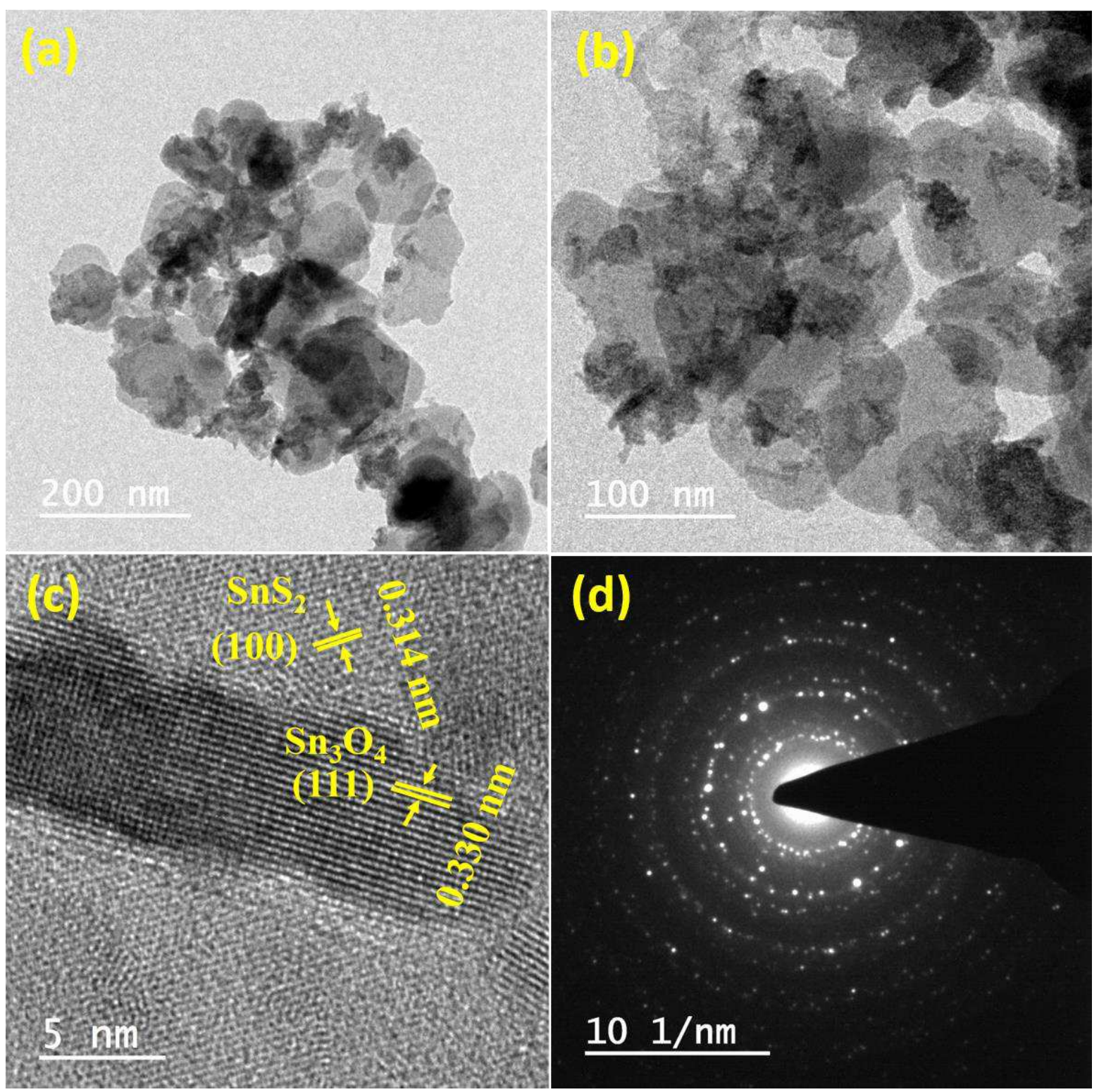

Fig. 2. 

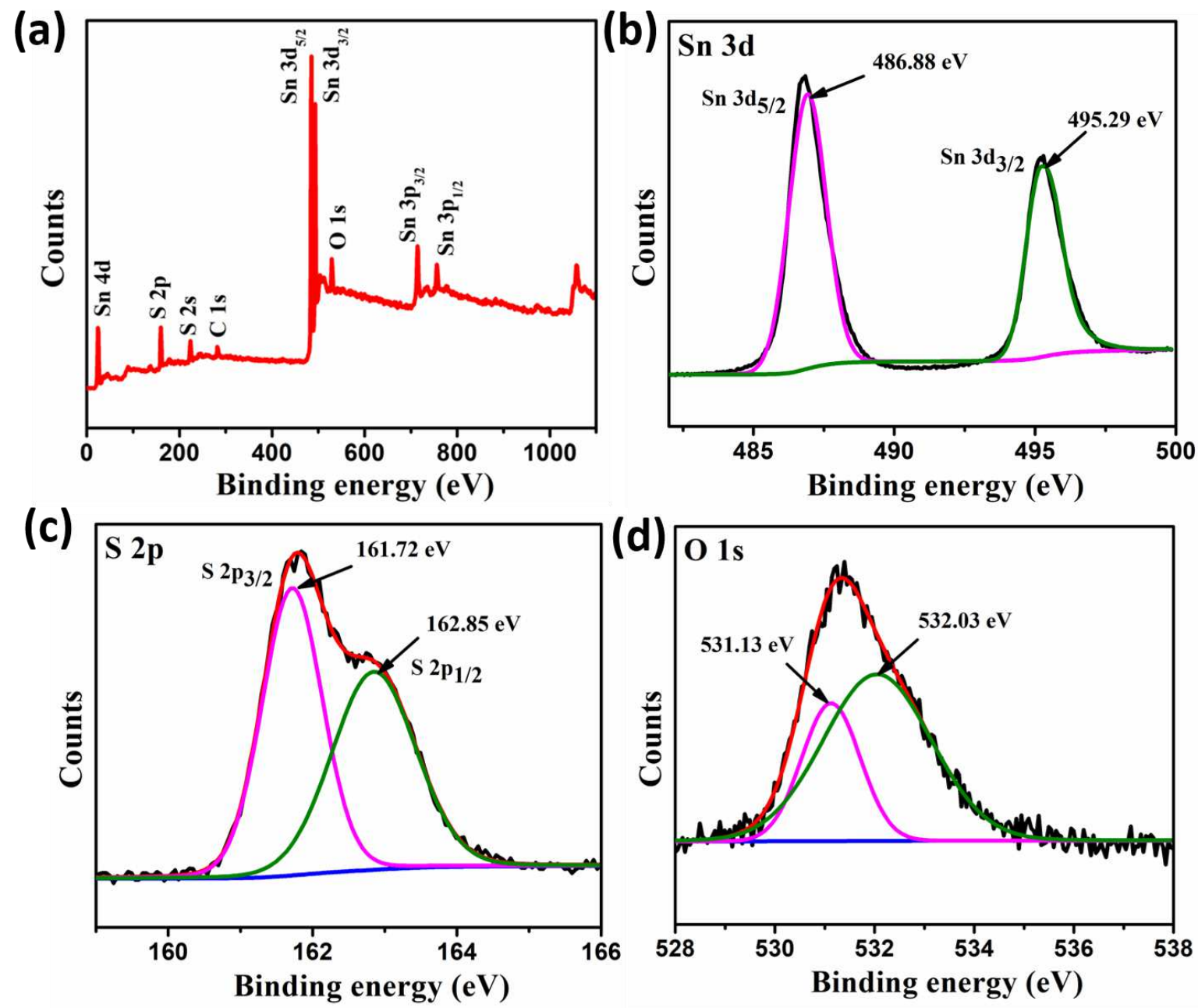

Fig. 3. 


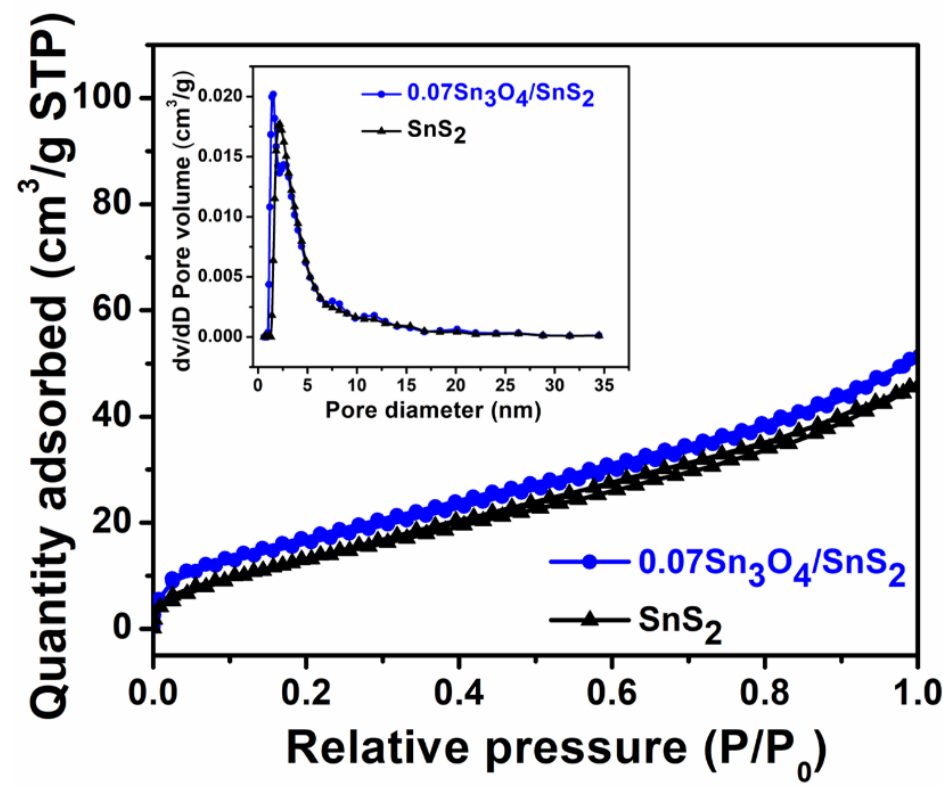

Fig. 4.

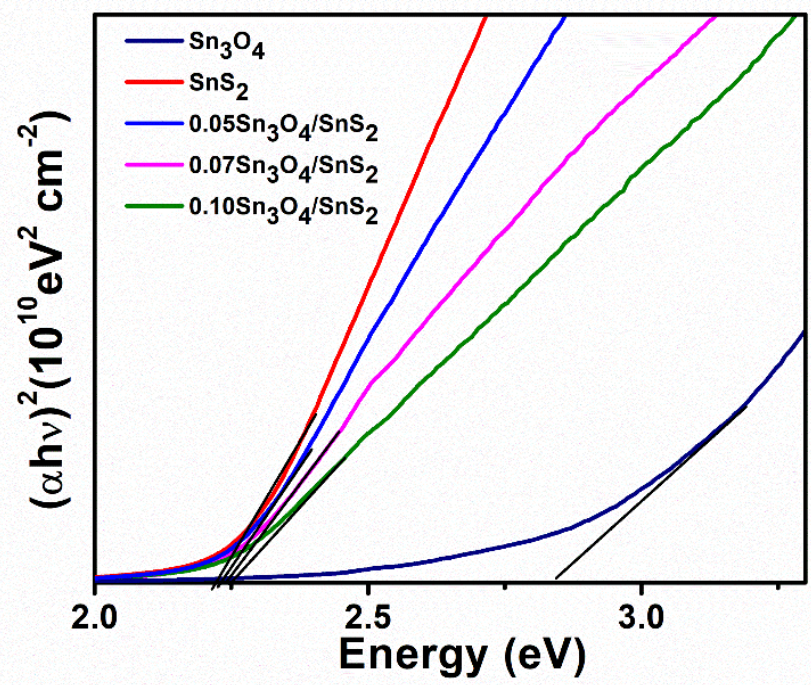

Fig. 5. 

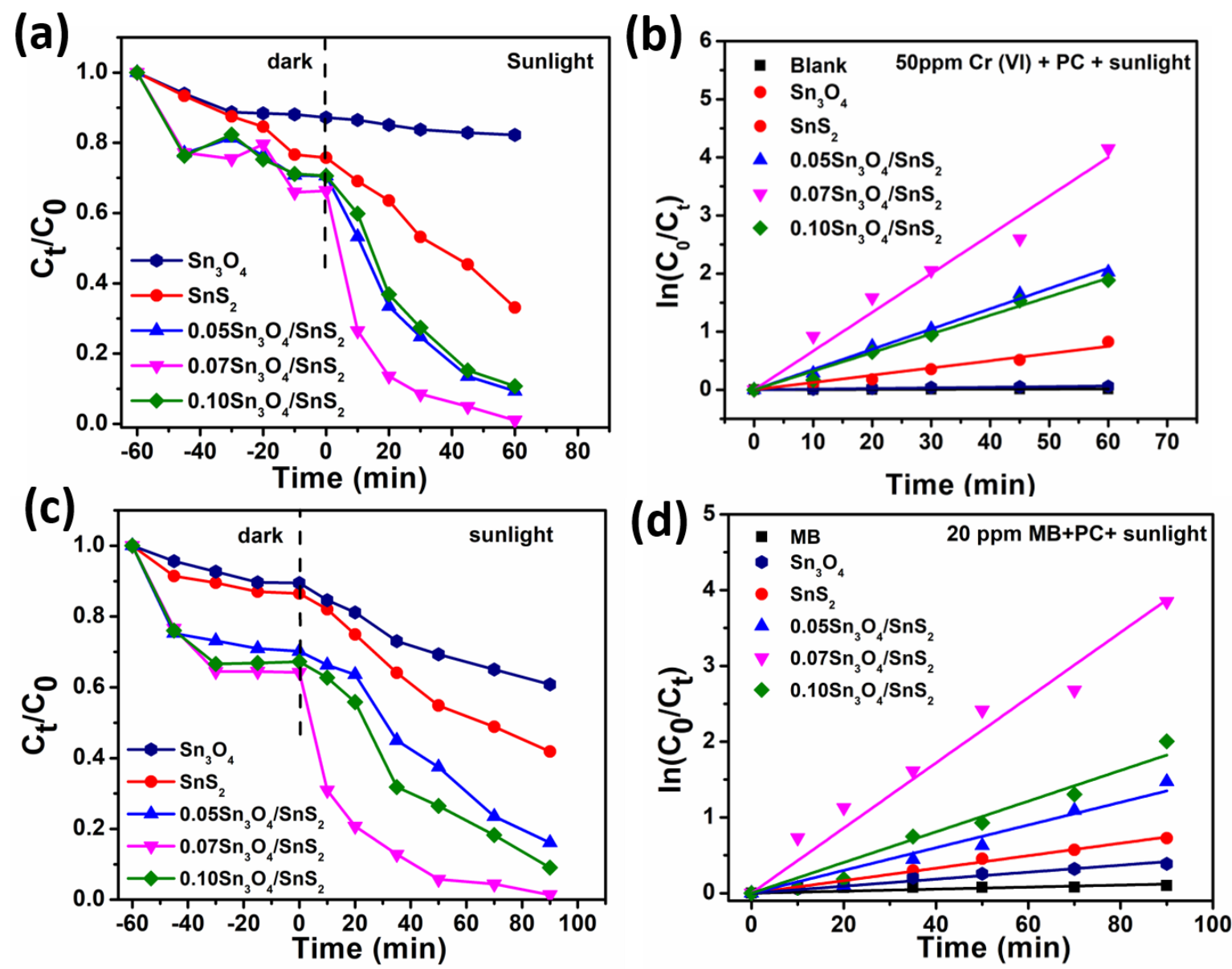

Fig. 6. 
(a)

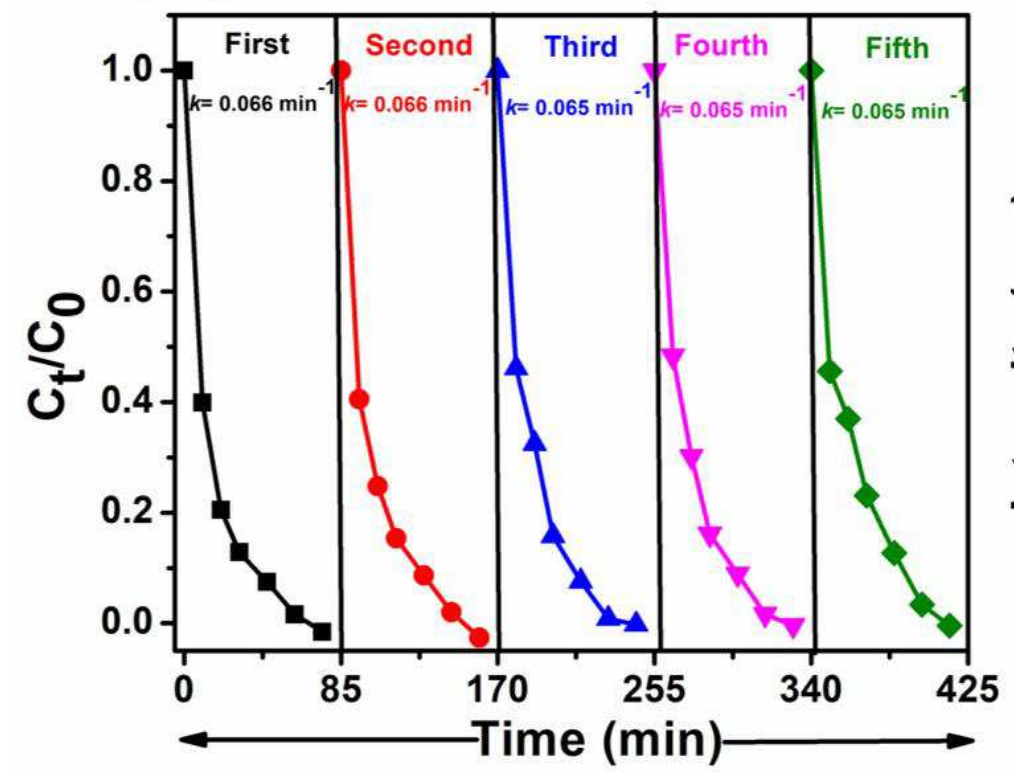

(b)

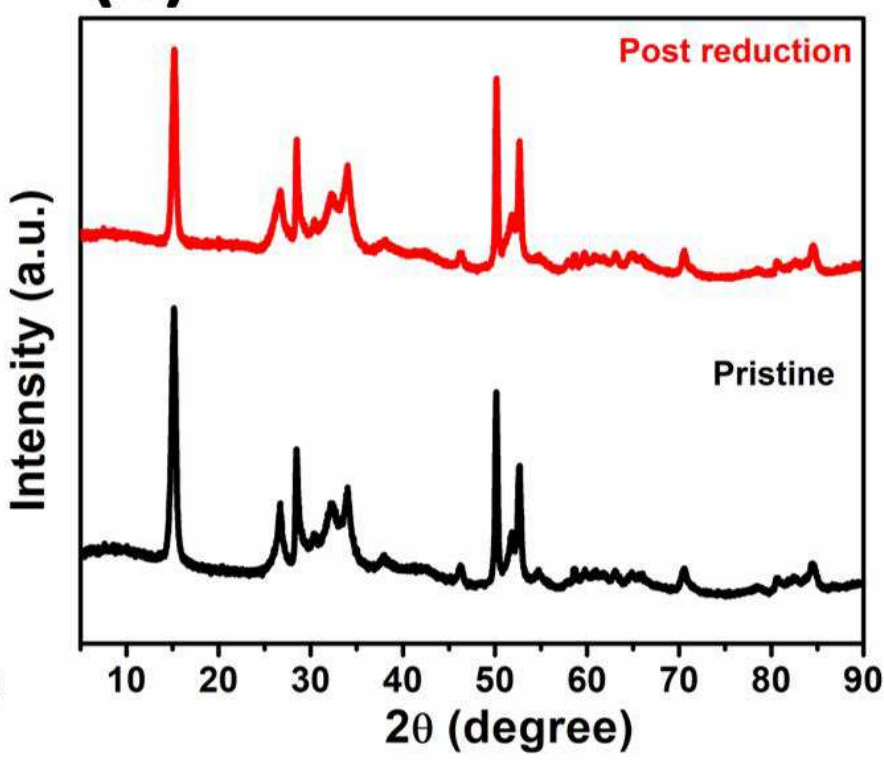

Fig. 7. (c)

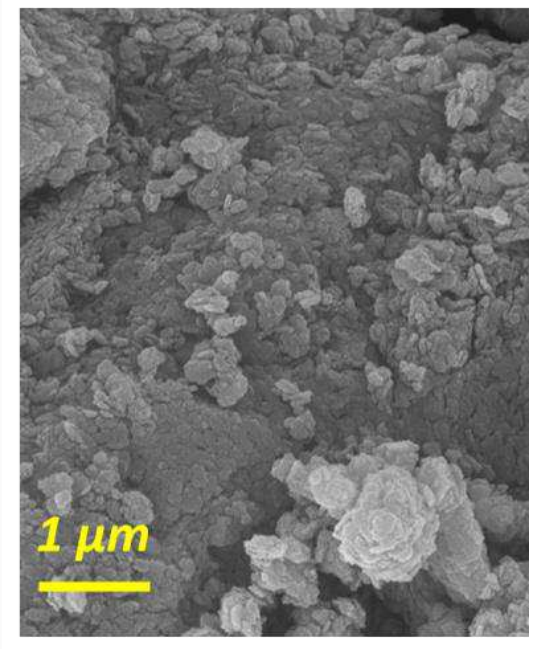



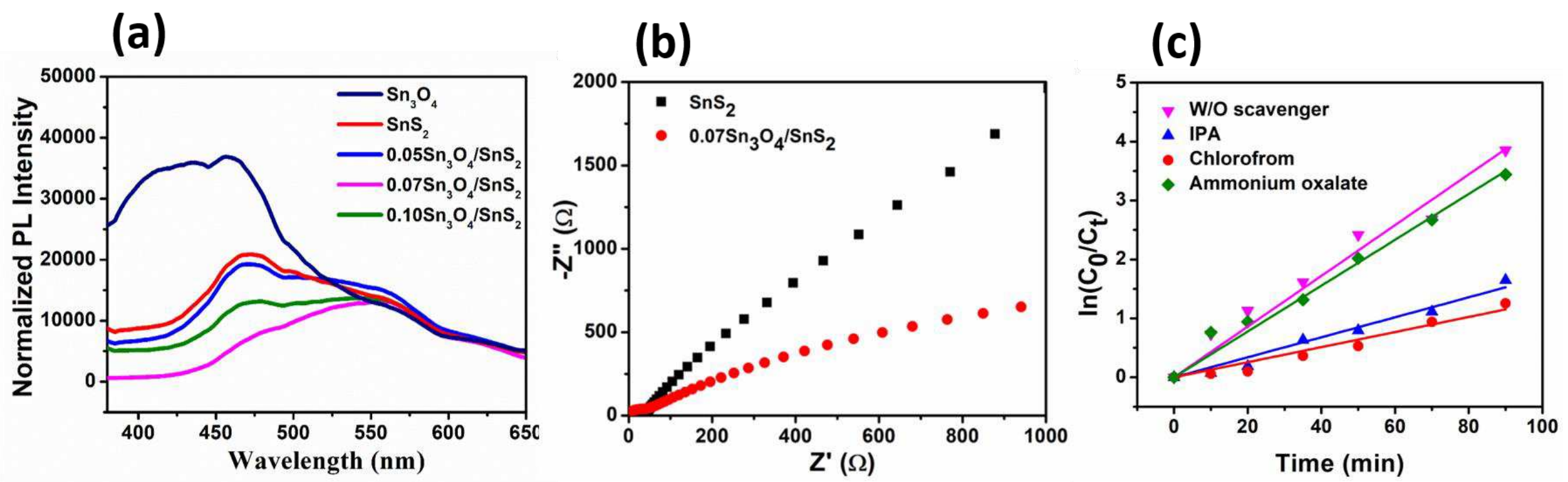

Fig. 8. 


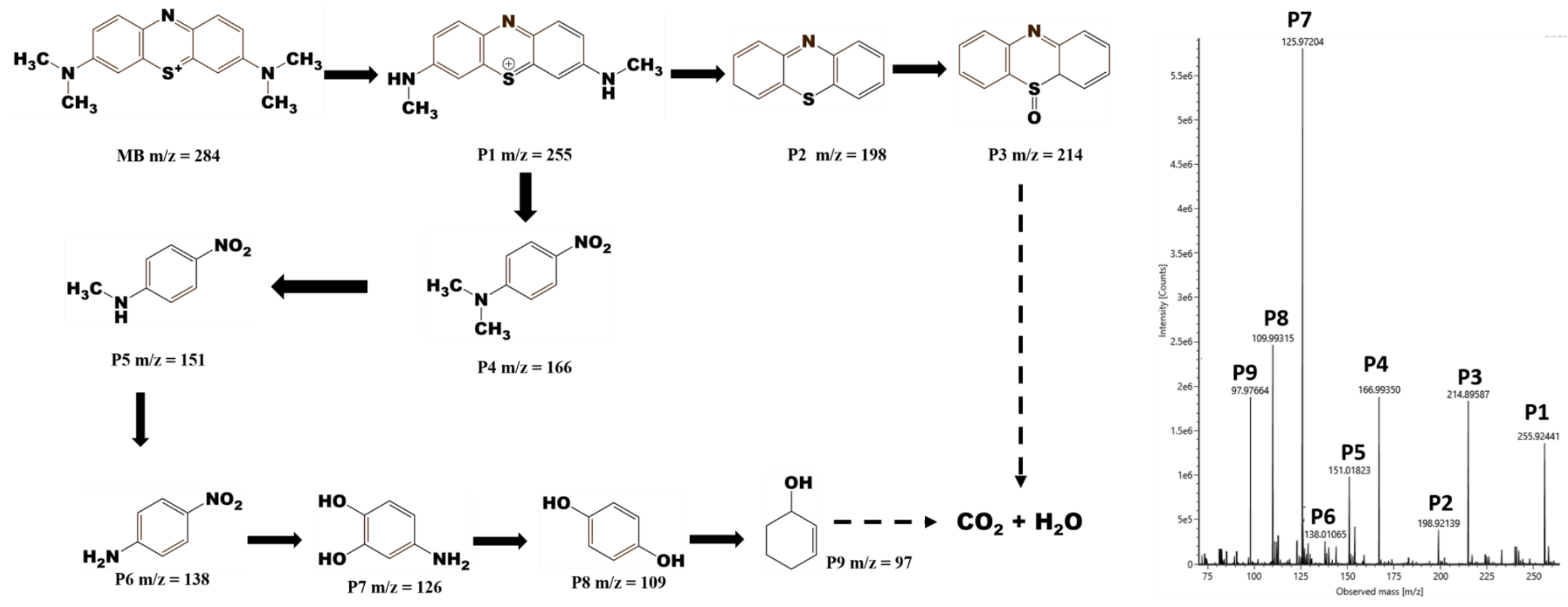

Scheme 1. 
(a)

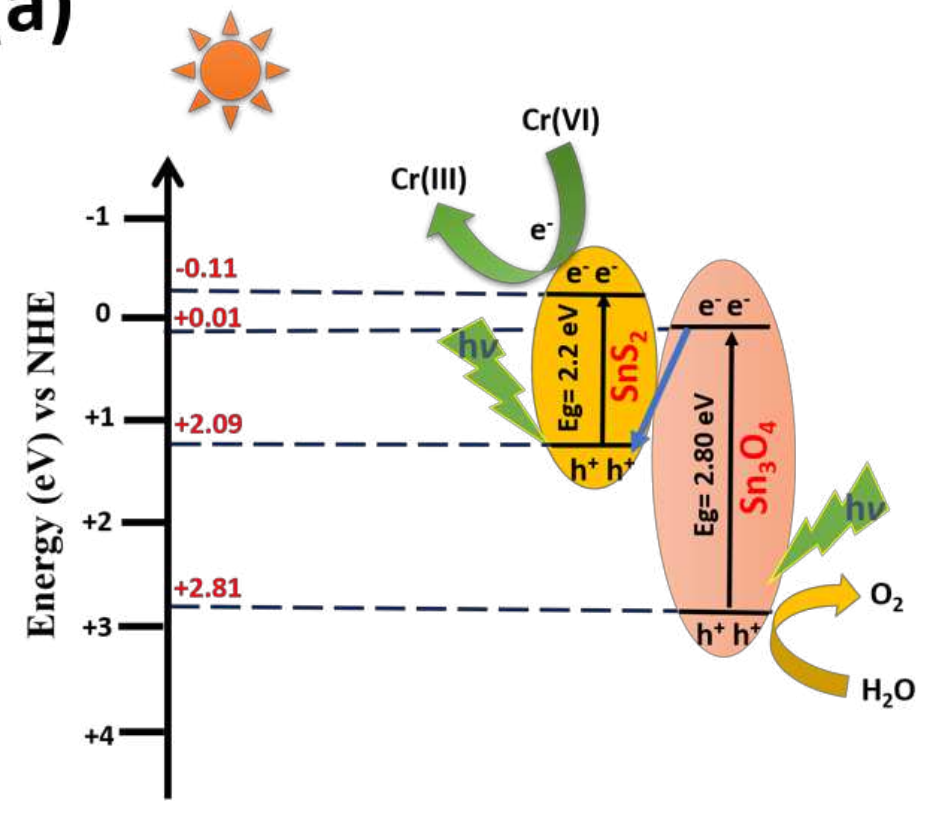

(b)

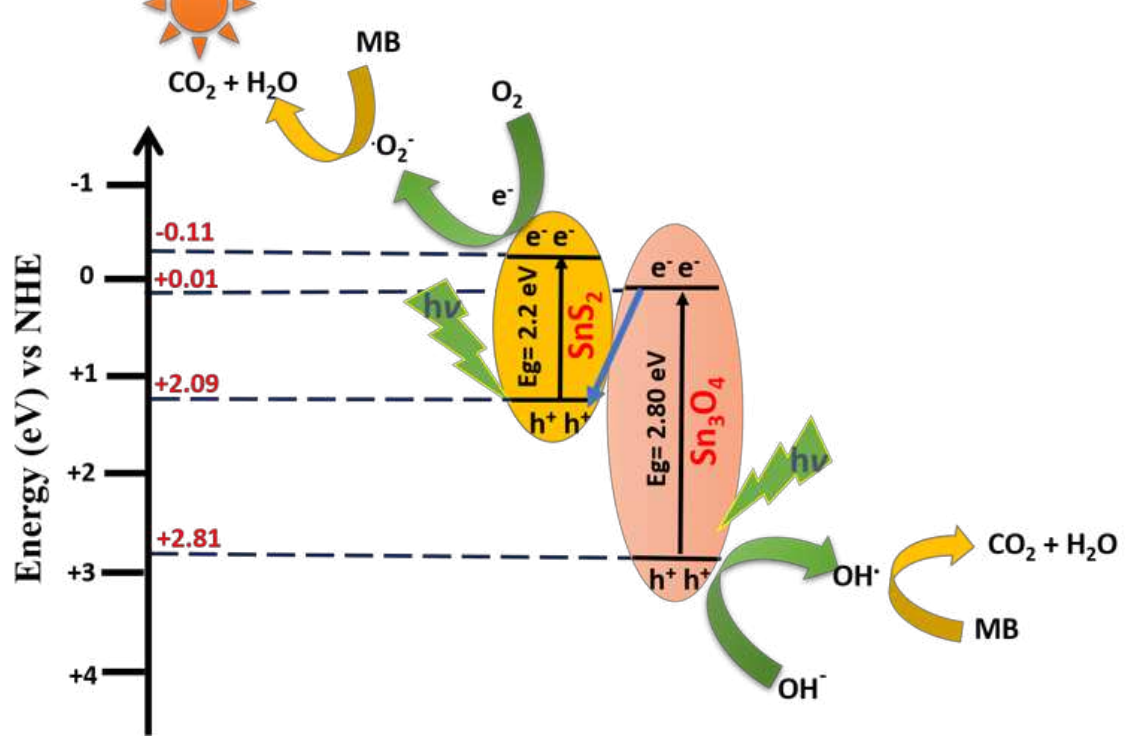

Scheme 2. 


\section{Supplementary Files}

This is a list of supplementary files associated with this preprint. Click to download.

- Sl.docx 